\title{
Molecular characteristics and laminar distribution of prefrontal neurons projecting to the mesolimbic system
}

\author{
Ákos Babiczky ${ }^{1,2,3}$, Ferenc Mátyás ${ }^{1,2,4, *}$ \\ 1 - Research Centre for Natural Sciences, H-1117, Budapest, Hungary \\ 2 - Institute of Experimental Medicine, $\mathrm{H}-1083$, Budapest, Hungary \\ 3 - Doctoral School of Psychology/Cognitive Science, Budapest University of Technology and Economics; \\ $\mathrm{H}-1111$, Budapest, Hungary \\ 4 - Department of Anatomy and Histology, University of Veterinary Medicine, H-1078, Budapest, \\ Hungary \\ *Corresponding author
}

\begin{abstract}
Prefrontal cortical influence over the mesolimbic system - including the nucleus accumbens (NAc) and the ventral tegmental area (VTA) - is implicated in various cognitive processes and behavioral malfunctions. The functional versatility of this system could be explained by an underlying anatomical complexity; however, the detailed characterization of the medial prefrontal cortical (mPFC) innervation of the NAc and VTA is still lacking. Therefore, combining classical retrograde and conditional viral tracing techniques with multiple fluorescent immunohistochemistry, we sought to deliver a precise, cell- and layer-specific anatomical description of the cortico-mesolimbic pathways. We demonstrated that NAc$\left(\mathrm{mPFC}_{\mathrm{NAC}}\right)$ and VTA-projecting mPFC (mPFC $\mathrm{VTA}$ ) populations show different laminar distribution (layers 2/3-5a and 5b-6, respectively) and express different molecular markers. Specifically, calbindin and Ntsr1 are specific to $\mathrm{MPFC}_{\mathrm{NAC}}$ neurons, while mPFC $\mathrm{VTA}_{\mathrm{A}}$ neurons express high levels of Ctip2 and FoxP2, indicating that these populations are mostly separated at the cellular level. We directly tested this with double retrograde tracing and Canine adenovirus type 2-mediated viral labelling and found that there is indeed minimal overlap between the two populations. Furthermore, whole-brain analysis revealed that the projection patter of these populations is also different throughout the brain. Taken together, we demonstrated that the NAc and the VTA are innervated by two, mostly non-overlapping mPFC populations with different laminar distribution and molecular profile. These results can contribute to the advancement in our understanding of mesocorticolimbic functions and its disorders in future studies.
\end{abstract}




\section{Introduction}

The medial prefrontal cortex (mPFC), the nucleus accumbens (NAc) and the ventral tegmental area (VTA) are the three major elements of the mesocorticolimbic system that controls a wide range of behaviors (Tzschentke and Schmidt, 2000; Russo and Nestler, 2013; Riga et al., 2014). mPFC provides the major source of glutamatergic input to the NAc (Brog et al., 1993; Asher and Lodge, 2012; Li et al., 2018) and to the VTA (Geisler and Zahm, 2005; Mahler and Aston-Jones, 2012; Faget et al., 2016). Direct mPFC innervation in the NAc has been implicated in various cognitive processes and malfunctions, such as attention regulation (Christakou et al., 2004), impulse control (Feja and Koch, 2015), addiction (Schmidt et al., 2005; Peters et al., 2008; Seif et al., 2013; Domingo-Rodriguez et al., 2020) and depression (Vialou et al., 2014). mPFC can also bidirectionally modulate neuronal activity in VTA, including NAc- and mPFCprojecting dopaminergic neurons (Gariano and Groves, 1988; Carr and Sesack, 2000; Lodge, 2011).

Accordingly, stimulation of excitatory neurons in the MPFC elicits dopamine release in the NAc via the VTA (Taber et al., 1995; Karreman and Moghaddam, 1996) and optogenetic activation of mPFC input in the VTA is reinforcing (Beier et al., 2015; Pan et al., 2021). Although, excitatory neurons in the mPFC are distributed in distinct layers and possess various projection patterns and molecular identity, it is not known how this diversity correlates to the above-mentioned cortical functions.

Several well established classification systems exist, based on anatomical, physiological, molecular and connectivity profile of excitatory neurons in primary motor/sensory neocortical areas (Harris et al., 2014, 2019; Harris and Shepherd, 2015; Baker et al., 2018; Bakken et al., 2021). A widely accepted one divides principal neurons to three major classes according to their laminar distribution and projection pattern. Intertelencephalic (IT) cells are present in layers 2-6 (L2-6) and project to ipsi- and contralateral neocortex and striatum. Neurons of the pyramidal tract (PT, also known as extratelencephalic) class are located mostly in the L5b and innervate mostly mesencephalic and diencephalic regions. The third, corticothalamic (CT) class is composed of neurons in the $\mathrm{L} 6$ that innervate the thalamus. However, some studies suggest that this classification might be oversimplified and not universally applicable to all cortical areas (Groh et al., 2010; Kim et al., 2015). Indeed, recent publications divided motor cortical neurons into even more new subclasses according to their genetic identity (Callaway et al., 2021; Zhang et al., 2021). Thus, detailed class-, layer- and cell-selective examination is necessary to validate traditional classification systems of cortical pyramidal neurons, also in the MPFC. 
The lack of wide-spread adoption of such specific experimental approaches in the mPFC might be the source of numerous contradictions and inconsistencies present in the mesocorticolimbic literature. For instance, in a recent publication, Kim et al. (2017) demonstrated that NAc- and VTAprojecting MPFC neurons are mostly separated at the cellular level, while other experiments investigating the target selectivity of mPFC cells yielded contradictory results (Thierry et al., 1983; Ferino et al., 1987; Cassell et al., 1989; Pinto and Sesack, 2000; Gabbott et al., 2005; Morishima and Kawaguchi, 2006; Vázquez-Borsetti et al., 2011; Stuber et al., 2011; Kim et al., 2017; Otis et al., 2017; Gao et al., 2020). Such inconsistencies could be resolved by applying combined layer- and cell-selective approaches.

Therefore, combining classical tracing techniques, conditional viral labelling, and multiple fluorescent staining, we have begun to describe the prefrontal innervation of the NAc and VTA in a class, layer- and cell-specific manner. Here we report that these two structures are innervated by two, rather non-overlapping mPFC neuron populations. While NAc-innervating neurons tend to be found in the $L 2 / 3$ and L5a, VTA-projecting cells are mostly localized in the L5b and L6, resembling IT and PT projection classes, respectively. Accordingly, these two populations express different combination of molecular markers and have different afferent connections throughout the brain. Furthermore, we found that in comparison with primer cortical areas, the mPFC differs in several cytoarchitectural features.

\section{Results}

\section{Distribution and molecular characterization of NAc-projecting mPFC cells}

In order to investigate the MPFC-NAc connection, first, we injected retrograde tracers Cholera toxin B subunit (CTB) or FluoroGold (FG) into the NAc (Fig. 1A-C). Injection sites included both the core (NACC) and shell (NAcSh) region (Fig. 1C). Retrogradely labelled NAc-projecting mPFC cells (mPFC $\mathrm{NAC}_{\text {) }}$ were present throughout the mPFC. To identify the exact subregional distribution of $\mathrm{MPFC}_{\mathrm{NAc}}$ neurons, we performed multiple fluorescent immunohistochemical $\left(\mathrm{IHC}_{\mathrm{Fluo}}\right)$ staining for different molecular markers. As it was previously reported (Mátyás et al., 2014), parvalbumin (PV) staining delineates the dorsal and ventral borders of the prelimbic (PrL) subregion of the mPFC (Fig. 1-1A, asterisk). Calbindin (Calb1) was used to define layer 2/3 (L2/3) (van Brederode et al., 1991; Sun et al., 2002) and the ventral border of the infralimbic cortex (IL), where the clearly visible L2/3 diminishes, as well as to visualize the thickening of L1, a characteristic of the deep peduncular cortex (DP) (Akhter et al., 2014) (Fig. 1-1B, number sign). COUP-TF-interacting protein 2 (Ctip2, also known as Bcl111b) was used to outline the L5b and L6 (Arlotta et al., 2005; Ueta et al., 2014; Kim et al., 2017) (Fig. 1-1C). Furthermore, forkhead box 
protein P2 (FoxP2) staining identifies the L6 (Ferland et al., 2003) and the gradual thinning and disappearance of a distinct L6 towards the ventralmost part of the MPFC (Fig. 1-1D, cross).
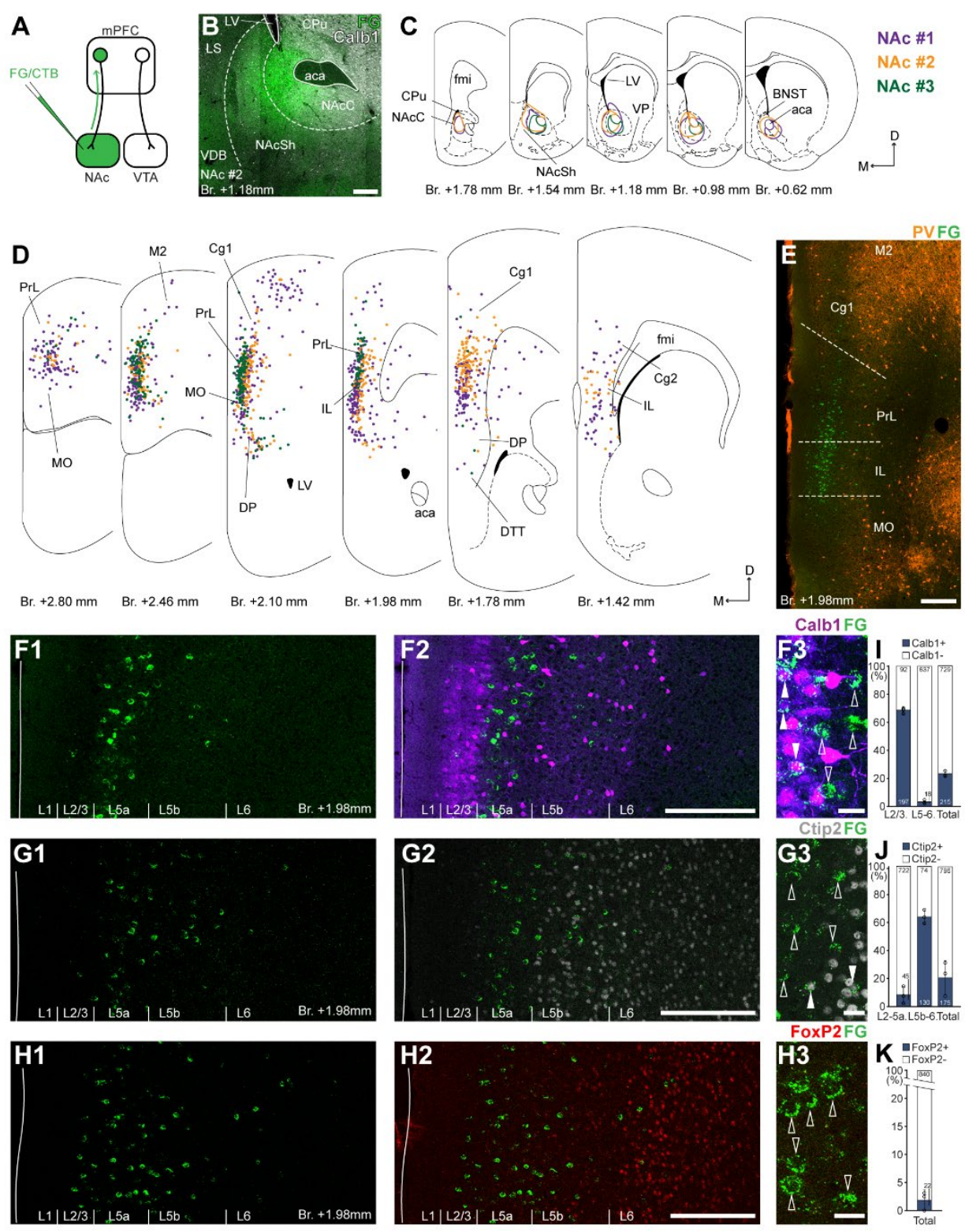

Figure 1. NAC is innervated by $L 2 / 3$ and $L 5$ mPFC cells. $\boldsymbol{A}$, Experimental design. $\boldsymbol{B}, \boldsymbol{A}$ representative retrograde tracer (FG, green) injection site in the NAc. C, Delineation of injection sites in the NAc of three animals. Each case is represented with different color. $D$, Plotted distribution of retrogradely labelled cells throughout the $m P F C$ of the same animals as in $\mathbf{C}$ (same colors represent same animals). Each dot represents one labelled $m P F C_{N A c} C e l l . E$, Distribution of labelled $M P F C_{N A c}$ neurons in relation to PV (orange) immunofluorescent labelling outlining the PrL cortex (Fig. 1-1). F-H, Confocal images showing the distribution of FG labelled cells (green) in the PrL (F1-H1) with the counterstaining of Calb1 (purple, F2), Ctip2 (grayscale, G2) and FoxP2 (red, H2) (Fig. 1-1). Note that most labelled cells are localized in the L2/3 (Calb1) and L5a (Ctip2). F3-H3, High magnification confocal images showing the coexpression of FG and Calb1 (F3), Ctip2 (G3) or FoxP2 (H3). White arrowheads indicate coexpression, empty arrowheads indicate the lack of marker expression. I-K, Bar graphs showing the proportion of Calb1- (I), Ctip2- (J) and FoxP2-expressing (K) mPFC ${ }_{N A c}$ cells. Numbers in the bars represent cell counts. Scale bars: B, E, F1-H1, F2-H2, 
$200 \mu \mathrm{m} ; \mathrm{F3}-\mathrm{H3}, 20 \mu \mathrm{m}$. aca, anterior commissure, anterior part; BNST, bed nucleus of the stria terminalis; CPu, caudate putamen; fmi, forceps minor of the corpus callosum; $L S$, lateral septum; $L V$, lateral ventricle; VDB, nucleus of the vertical limb of the diagonal band; VP, ventral pallidum. All data are shown as mean $\pm S D$.
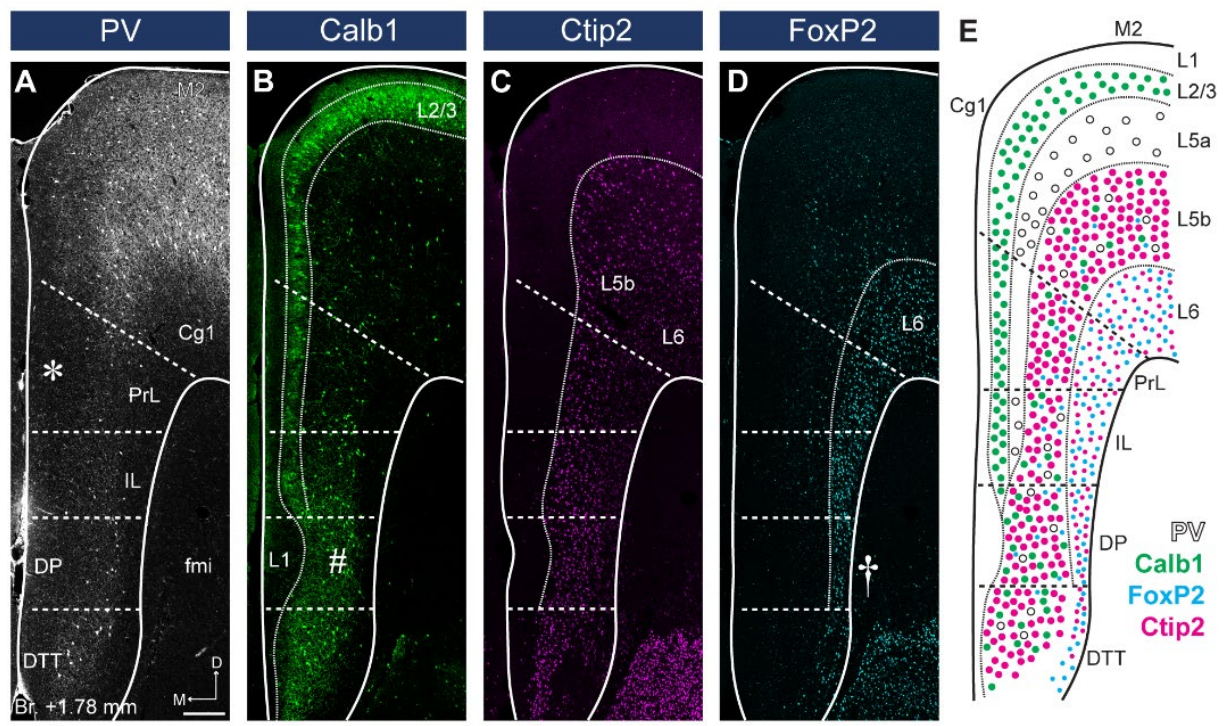

Figure 1-1. PV, Calb1, Ctip2 and FoxP2 staining define mPFC subregion borders and layers. A, The lack of PV+ axonal and cellular immunolabeling (grayscale) in the L2/3 defines the territory of PrL (asterisk). B, Calb1expressing L2/3 (green) is clearly visible in most parts of the MPFC. A thickened L1 and a more compact L2/3 and L5 identifies the DP (number sign). C, Ctip2 (magenta) is expressed in the L5b (bigger neurons) and L6 (smaller neurons). D, FoxP2 (cyan) is expressed throughout the L6 of the MPFC. Narrowed L6 and the lack of FoxP2expressing cells (cyan) in the $L 5$ reveal DP (cross). E, Schematic summary of PV, Calb1, FoxP2 and Ctip2 distribution in the MPFC. Scale bar: $200 \mu \mathrm{m}$.

According to the obtained molecular-based mPFC map, most mPFC $\mathrm{NAc}_{\mathrm{N}}$ neurons were found in the PrL, medial orbital (MO) and IL subregions and, to a lower extent, in the DP, cingulate area 1-2 (Cg12) and secondary motor (M2) cortices. Only a few cells were found in the dorsal tenia tecta (DTT, also known as anterior hippocampal continuation), primary motor (M1) and the adjacent orbital cortices (Fig. $1 D-E)$.

Next, we analyzed the laminar distribution of the retrogradely labelled cells using $I H C_{\text {Fluo }}$ against Calb1, Ctip2 and FoxP2 (Fig. 1F-H, Fig. 1-1). This analysis revealed that most $\mathrm{mPFC}_{\mathrm{NAc}}$ neurons localized in the Calb1-rich L2/3 and in the L5a, and, to a lower extent, in the L5b (Fig. 1F-G). Only a small number of cells were found in the FoxP2-expressing L6 (Fig. $1 H$ ).

To characterize the molecular identity of $\mathrm{mPFC}_{\mathrm{NAc}}$ cells, we quantified their Calb1-, Ctip2 and FoxP2-expression (Fig. 1, F3-H3, J-K). Our analysis revealed that about two-thirds $(68.64 \pm 2.62 \%, n=3$ animals, $N_{\text {Calb1+/FG+ }}=197 / 289$ cells; Fig. $1 F 3$, l, left bar; Table 1 ) of $m P F C_{N A c}$ neurons in the L2/3 expressed Calb1, while only a small proportion did so in the L5-6 (2.87 $\pm 1.15 \%, N_{\text {Calb } 1+/ F G+}=18 / 655$ cells; Fig. 1 , 


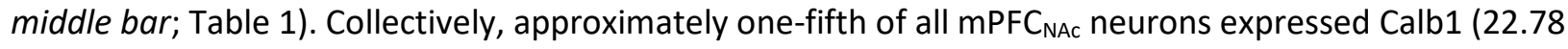
$\pm 1.86 \%, N_{\text {calb1+/FG+ }}=215 / 944$ cells; Fig. 21 , right bar; Table 1). Although most of the $\mathrm{PPFC}_{\mathrm{NAc}}$ cells were found in the Ctip2-negative L2/3 and 5a, some cells were found in the deeper layers as well. Confocal analysis revealed that only a small proportion of superficial (i.e., L2/3-5a) cells are Ctip2-positive (8.26 \pm $2.6 \%, n=3$ animals, $N_{C t i p 2+/ F G+}=45 / 767$ cells; Fig. 1G3, J, left bar; Table 1), while in the deeper layers (i.e., L5b-6), although relatively few in number, the majority of cells expressed Ctip2 $\left(64.1 \pm 4.76 \%, N_{\text {Ctip } 2+/ F G+}=\right.$ 130/204 cells; Fig. 1J, middle bar; Table 1). Collectively, approximately one-fifth of all mPFC $\mathrm{NAc}_{\text {c }}$ cells expressed Ctip2 (20.8 $\pm 12.1 \%, N_{C t i p 2+/ / F+}=175 / 971$ cells; Fig. 1J, left bar; Table 1$)$. Finally, only a negligible number of $\mathrm{mPFC}_{\mathrm{NAc}}$ cells expressed FoxP2 $\left(2.11 \pm 1.84 \%, n=3\right.$ animals, $N_{\text {FoxP2 } / / F G+}=22 / 862$ cells, Fig. $1 H 3, K$; Table 1$)$.

Altogether, retrograde tracing experiments revealed that $\mathrm{MPFC}_{\mathrm{NAc}}$ neurons were mostly localized in the L2/3 and 5a of the PrL, MO and IL cortices. Approximately one-fifth of these cells express Calb1 - most of them are localized in the $L 2 / 3$, where Calb1 expression is higher ( $70 \%$ ) -, and another one-fifth express Ctip2, mostly in the L5b-6.

\section{Distribution and molecular characterization of VTA-projecting mPFC cells}

Next, we investigated the distribution of VTA-projecting neurons in the MPFC (mPFC VTA). We used the previously described retrograde tracing approach in the VTA (Fig. 2A) identified with IHC Fluo against tyrosine hydroxylase (TH; Fig. 2B-C) (Oades and Halliday, 1987; Morales and Margolis, 2017). Most mPFC $C_{\mathrm{VTA}}$ neurons were localized in the PrL, MO, Cg1-2, IL and DP cortices (Fig. 2D-E). There were also several labelled cells in the adjacent orbital and motor cortices as well as in the DTT (Fig. 2D).

Regarding their laminar distribution, we found that there were two main clusters of $\mathrm{MPFC}$ VTA cells (Fig. 2D, F-H). One, visually smaller population was found in the more superficial part of the posterior MO, PrL and Cg1, and throughout the Cg2, IL and DP cortices (Fig. 2D). Cells in this cluster were mostly localized close to the border of L5a and L5b (Fig. 2F-G). The other cluster was found in the deeper parts (L5b-L6) of the anterior MO, PrL and Cg1, and posterior IL and DP cortices (Fig. 2D, H). The separation of these two mPFC $\mathrm{VTA}_{\mathrm{VA}}$ clusters was most prominent between Bregma $+1.2-1.8 \mathrm{~mm}$, as it was also shown in previous publications (Geisler and Zahm, 2005; Mahler and Aston-Jones, 2012). 

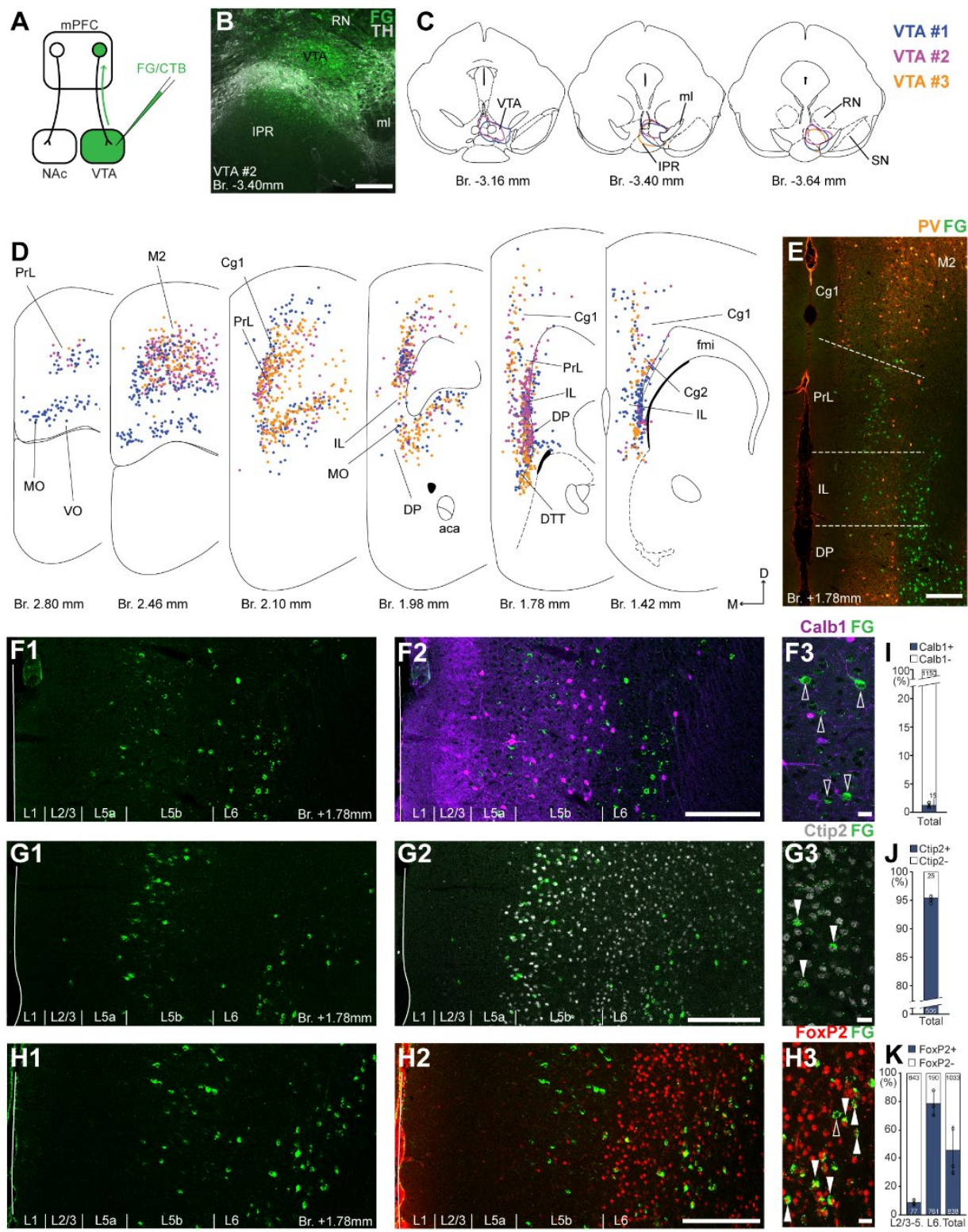

Figure 2. VTA is innervated by two MPFC cell clusters. A, Experimental design. B, A representative retrograde tracer (FG, green) injection site in the VTA. C, Full extent of the injection sites in the VTA in three animals. Each case is represented with different color. $D$, Plotted distribution of retrogradely labelled neurons throughout the mPFC of the same animals as in C (same colors represent same animals). Each dot represents one labelled mPFCVTA cell. E, Distribution of labelled neurons in the MPFC in relation to PV (orange) immunofluorescent labelling outlining the PrL cortex. F-H, Confocal images showing the layer-specific distribution of FG labelled cells (green) in the PrL (F1-H1) with counterstaining of Calb1 (purple, F2), Ctip2 (grayscale, G2) and FoxP2 (red, H2). Note that the labelled cells are almost exclusively localized in the L5b (Ctip2) and L6 (Ctip2+FoxP2) layers. F3-H3, High magnification confocal images showing the coexpression of FG and Calb1 (F3), Ctip2 (G3) or FoxP2 (H3). White arrowheads indicate coexpression, empty arrowheads indicate the lack of marker expression. I-K, Bar graphs showing the proportion of Calb1- (I), Ctip2- (J) and FoxP2-expressing (K) MPFCVTA cells. Numbers in the bars represent cell counts. Scale bars: $\boldsymbol{B}$, E, F1-H1, F2-H2, $200 \mu \mathrm{m} ; \mathbf{F 3 - H 3 ,} 20 \mu \mathrm{m}$. aca, anterior commissure, anterior part; fmi, forceps minor of the corpus callosum; IPR, interpeduncular nucleus, rostral subnucleus; $\mathrm{ml}$, medial lemniscus; $R \mathrm{~N}$, red nucleus; SN, substantia nigra; VO, ventral orbital cortex. All data are shown as mean $\pm S D$. 
Higher magnification confocal analysis revealed that only a marginal proportion $(1.31 \pm 0.5 \%, n=$

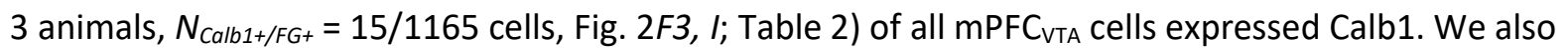
quantified the Ctip2-expression of MPFC $\mathrm{VTA}_{\mathrm{A}}$ neurons and found that the vast majority of these cells express Ctip2 (95.07 $\pm 0.6 \%, n=3$ animals, $N_{C t i p 2+/ F G+}=481 / 506$ cells; Fig. 2G3, J; Table 2). This finding is in accordance with previous results (Kim et al., 2017) showing CTIP2 gene enrichment in MPFC neurons. Finally, most L6 mPFC $\mathrm{VTA}_{\mathrm{A}}$ cells expressed FoxP2 $\left(78.86 \pm 8.79 \%, n=3\right.$ animals, $N_{\text {FoxP2+/FG }}=$ 761/951 cells; Fig. 2H3, K, middle bar; Table 2). On the other hand, in the superficial layers (L2/3-L5), only a small proportion ( $8.69 \pm 2.13 \%, N_{\text {FoxP2 }+/ F G+}=77 / 920$ cells; Table 2$)$ of $\mathrm{mPFC}$ VTA cells were FoxP2positive (Fig. $1 K$, left bar). In total, about half of all mPFC $\mathrm{VTA}_{\mathrm{A}}$ neurons expressed FoxP2 (45.93 $\pm 17.15 \%$, $N_{\text {FoxP } 2+/ F G+}=838 / 1871$ cells; Fig. $2 K$, right bar; Table 2 ).

Taken together, using retrograde tracing experiments we identified two clusters of MPFC VTA neurons distributed throughout the MPFC: one FoxP2-, and most probably Ctip2-expressing population localized mostly in the L6 (approximately half of all neurons); and one, mostly FoxP2-negative, but Ctip2positive population in the layer $5 b$.

\section{Utility of Cre mouse lines to label mPFC neurons in a layer-selective manner}

We found retrogradely labelled $\mathrm{MPFC}_{\mathrm{NAC}}$ and $\mathrm{mPFC} \mathrm{VTA}_{\mathrm{V}}$ neurons in all cellular layers of the mPFC in varying densities. Next, we sought to confirm the laminar organizations of the projecting cells using transgenic mice expressing Cre-recombinase enzyme in a layer-selective manner. We used the following layer-specific Cre-expressing mouse strains: Calb1- (L2/3), Retinol Binding Protein 4- (Rbp4; L5), Neurotensin Receptor 1 (Ntsr1; L6) and FoxP2-Cre (L6) (van Brederode et al., 1991; Hof et al., 1999; Sun et al., 2002; Ferland et al., 2003; Molyneaux et al., 2007; Harris et al., 2014, 2019; Sundberg et al., 2018; Callaway et al., 2021; Matho et al., 2021; Muñoz-Castañeda et al., 2021) in combination with Credependent adeno-associated viral vectors (AAVs) (Fig. 3A-E). Furthermore, we used a Thymocyte differentiation antigen 1 (Thy1)-Cre mouse line as control, in which Cre enzyme is expressed in all pyramidal neurons, regardless of their laminar localization (Fig. 3F).

Virally labelled cell bodies in all strains were primarily found in the $\operatorname{PrL}, \mathrm{IL}, \mathrm{Cg} 1-2, \mathrm{MO}$, and, to a lower extent, in the DP, the ventromedial M2, the dorsal part of the DTT and the medial part of the VO cortex (Fig. 3B-F) in good correspondence with the distribution of the retrogradely labelled $\mathrm{mPFC}_{\mathrm{NAC}}$ and mPFC $_{V T A}$ neurons (Fig. 1, Fig. 2). Note that viral expression was always analyzed after IHC-enhancement 
of eYFP/mCherry, because this method revealed structures - mostly thin axon-branches, but also some cell bodies - and fine details (e.g., dendritic spines) otherwise not detectable (see Methods) (Fig. 3-1).

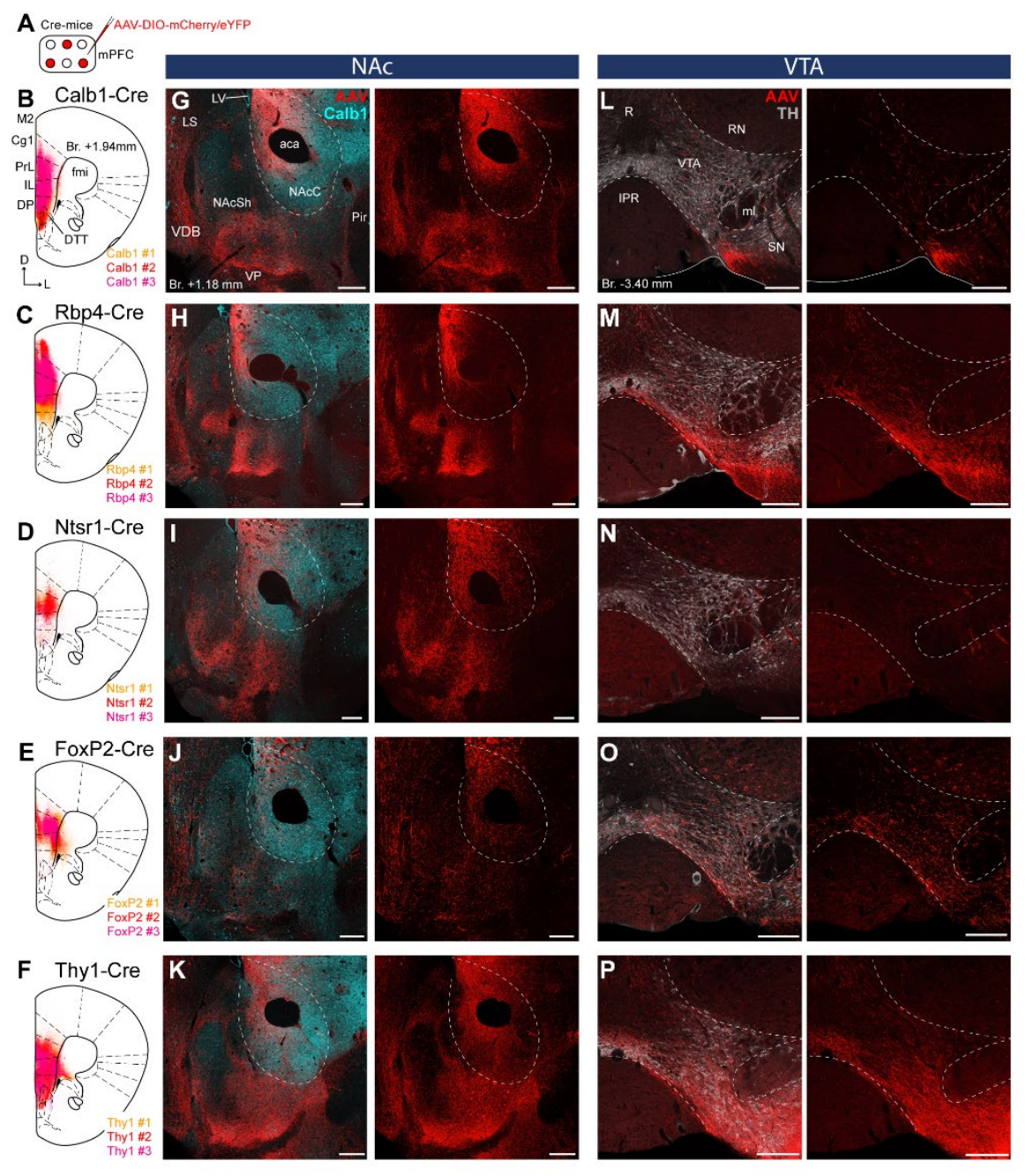

Figure 3. Distinct NAC and VTA innervation by genetically identified mPFC cell populations. A, Experimental design. B-F, Delineation of viral injection sites in the mPFC of 3-3 animals of the Calb1- (B), Rbp4- (C), Ntsr1- (D), FoxP2- (E) and Thy1-Cre (F) strains. Viral labelling was always analyzed after immunohistochemical enhancement (Fig. 3-1). For detailed distribution of labelled cells in the MPFC and M1 see Fig. 3-2. G-K, Confocal images showing virally labelled prefrontal axons (red) in the NAc of Calb1-Cre (G), Rbp4-Cre (H), Ntsr1-Cre (I), FoxP2-Cre (J) and Thy1-Cre (K) mouse strains. Calb1 (cyan) immunofluorescent staining was used to identify the NAcC. L-P, Distribution of labelled axons (red) from the same animals (respectively) in the VTA defined with TH staining (grayscale). Scale bars: $200 \mu \mathrm{m}$. aca, anterior commissure, anterior part; fmi, forceps minor of the corpus callosum; IPR, interpeduncular nucleus, rostral subnucleus; $L S$, lateral septum; LV, lateral ventricle; ml, medial lemniscus; Pir, piriform cortex; $R$, raphe; $R N$, red nucleus; $S N$, substantia nigra; VDB, nucleus of the vertical limb of the diagonal band; VP, ventral pallidum. 

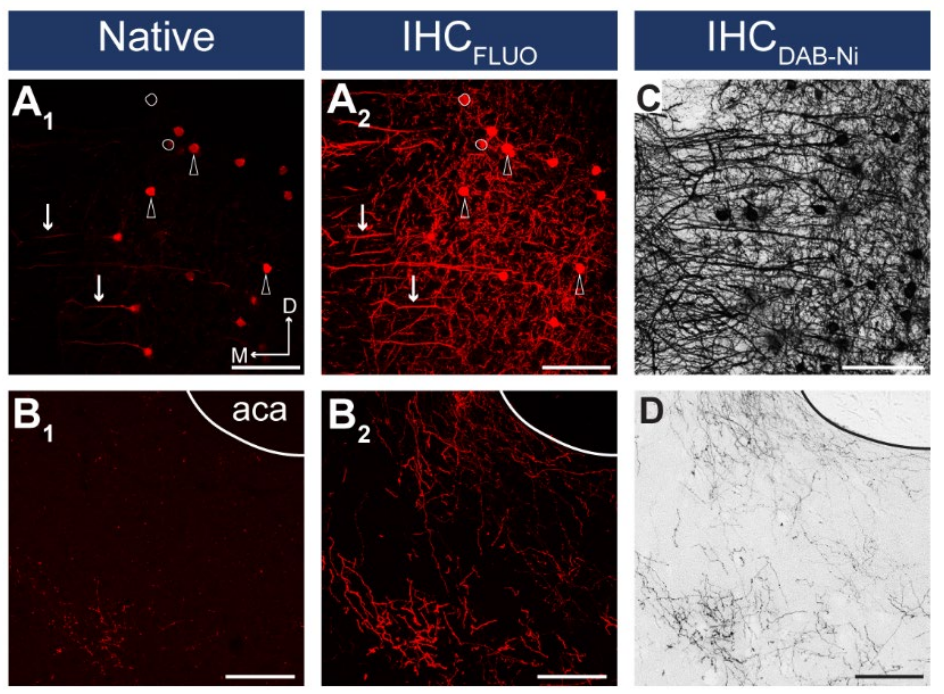

Figure 3-1. IHC enhancement is necessary for reliable detection of viral fluorescent signal. $\mathbf{A}-\boldsymbol{B}$, Confocal images showing the native $m$ Cherry signals in the somatodendritic (A1) and axonal compartments (B1) and after IHCFluo signal-enhancement (A2-B2) of the same slice taken from the mPFC (A, injection site) and from the NAc (B). Arrows indicate dendrites, arrowheads indicate neurons visible in both the native and $\mathrm{IHC}_{\mathrm{Flu}}$-enhanced sample. White circles indicate neurons not visible in the native sample. C-D, Brightfield images showing IHCDA-Ni-enhanced samples taken from a neighboring slice. Scale bars: $100 \mu \mathrm{m}$. aca, anterior commissure, anterior part.

Since the majority of previous publications describing cortical layer-specific markers focused on primary cortical areas, we compared the expression pattern of virally labelled cells in the mPFC - a higher-order cortical region - (Fig. 3-2A-E) and in the primary motor cortex (M1, Fig. 3-2F-J) - a primary frontal cortical area - in each mouse strain. Labelled cells in the Calb1-Cre animals showed similar distribution in both cortical areas: most of them were found in the L2/3 with scattered cells in the L5 (Fig. 3-2A, F) (Muñoz-Castañeda et al., 2021). Interestingly, Rbp4-, and Ntsr1-expressing cells showed somewhat different distribution in the two cortical regions (Fig. 3-2B-C, G-H). In the Rbp4-Cre strain, virally labelled cells in the mPFC were found to some extent in the L2/3 - especially in the ventral part of the MPFC, in the IL and DP - besides the well-known L5 location. In the M1, only the L5 population was present (Callaway et al., 2021; Muñoz-Castañeda et al., 2021) (Fig. 3-2B, G). In the Ntsr1-Cre animals, no virally labelled neurons were found in the L6 in the MPFC, only in the L5a (Fig. 3-2C). In the M1 cortex, Ntsr1-expressing labelled cells were found exclusively in the L6, as it was previously reported (DeNardo et al., 2015; Tasic et al., 2016; Sundberg et al., 2018; Callaway et al., 2021; Muñoz-Castañeda et al., 2021) (Fig. 3-2H). In the Foxp2- and Thy1-Cre animals we did not observe any difference between the two cortical regions: AAV transduced cells were found in the L6 (Fig. 3-2D, I), or in all cellular layers of the mPFC (Fig. 3-2E) and the M1 (Fig. 3-2J), respectively. 

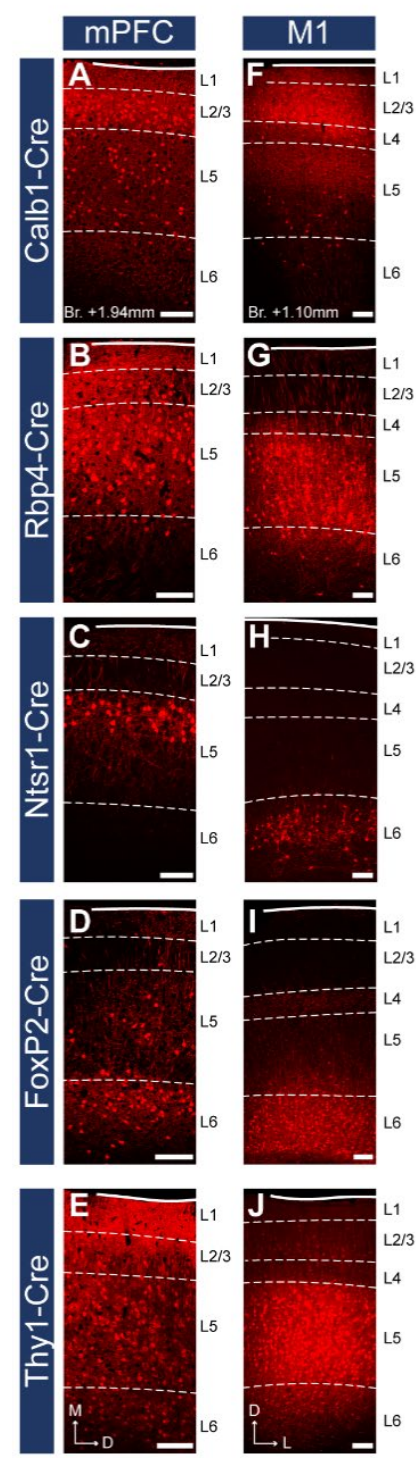

Figure 3-2. Layer-specific Cre mouse lines reveal different laminal distribution of mPFC and primary motor cortical cells. A-E, Confocal images showing the AAV labelled cells in the MPFC in the same animals as in Fig. 3 (respectively). F-J, Localization of labelled neurons in the $\mathrm{M} 1$ cortex in the same mouse strains. Note the different distribution of Rbp4- $(\boldsymbol{B}, \boldsymbol{G})$ and Ntsr1-expressing $(\boldsymbol{C}, \boldsymbol{H})$ cells in the two cortical regions. Dashed lines indicate layer borders defined with IHCFluo against Calb1, Ctip2 or FoxP2 (Fig. 1-2). Scale bars: $200 \mu \mathrm{m}$.

Together, these results show that these mouse strains can be used to label and investigate distinct layers of prefrontal cell populations, confirming previous findings (van Brederode et al., 1991; Hof et al., 1999; Sun et al., 2002; Ferland et al., 2003; Molyneaux et al., 2007; Harris et al., 2014, 2019; Sundberg et al., 2018; Callaway et al., 2021; Matho et al., 2021; Muñoz-Castañeda et al., 2021). However, in some cases (Rbp4-, Ntsr1-Cre) the distribution of labelled neurons was somewhat different in the MPFC compared to M1. 


\section{Layer-selective prefrontal cortical innervation of the NAC and VTA}

After validating the use of these Cre mouse strains and AAV vectors to label mPFC neuron populations in a layer-selective manner, we sought to explore their projection patterns in the NAc and VTA. In order to do this, we performed confocal microscopy combined with multiple $\mathrm{IHC}_{\text {Fluo }}$ in tissue samples taken from the MPFC animals described in the previous section.

In the Calb1-Cre strain - where viral transduced cells were confined to the $L 2 / 3$ - labelled axons were found in the NAc (Fig. 3G) but not in the VTA (Fig. 3L). These results are in accordance with our retrograde tracing results showing that a high proportion of $\mathrm{mPFC}_{\mathrm{NAC}}$ neurons in the $\mathrm{L} 2 / 3$ express Calb1 (Fig. 1), and the lack of mPFC VTA cells in the Calb1-rich layer 2/3 (Fig. 2). In the Rbp4-Cre animals (L2/3-5), AAV labelled axons were found both in the NAc (Fig. 3H) and VTA (Fig. 3M) also confirming our retrograde tracing result (Fig. 1, Fig. 2). Ntsr1-Cre expressing cells - localized in the L5a (Fig. 3-1C), where most of the mPFC $\mathrm{NAc}_{\mathrm{c}}$ neurons were found previously (Fig. 1) - projected to the NAc with visually dense arborization (Fig. 3/) but avoided the VTA (Fig. 3N). In the FoxP2-Cre strain (L6), only a small number of AAV-labeled axons was present in the NAc (Fig. 3J), while a relatively dense arborization of labelled axons was found in the VTA (Fig. 3O). This is in good accordance with our previous findings demonstrating that only a marginal proportion of $\mathrm{mPFC}_{\mathrm{NAC}}$ neurons express FoxP2 (Fig. 1), while almost half of all mPFC $C_{\text {VTA }}$ cells does so (Fig. 2). Finally, in the control Thy1-Cre strain we observed dense axonal arborization both in the NAc (Fig. $3 K$ ) and VTA (Fig. 3P).

Taken together, our classical retrograde and cell type-specific anterograde viral tracing experiments revealed that $\mathrm{MPFC}_{\mathrm{NAc}}$ and $\mathrm{MPFC} \mathrm{VTA}_{\mathrm{A}}$ neuron populations are mostly separated in the L2/3$5 a$ and L5b-6 (respectively), although this separation is not exclusive. Conversely, these populations seem to overlap in the $L 5$, but it is not clear whether a single mPFC neuron projects to both targets simultaneously or shows target selectivity.

\section{NAc- and VTA-projecting mPFC populations are mostly non-overlapping}

Next, we aimed to answer the open question whether a single mPFC can innervate the NAc and VTA simultaneously or not. Although previous studies investigated the target selectivity of mPFC neurons extensively, some reported relatively high ratio of multiple-projection (Thierry et al., 1983; Ferino et al., 1987; Cassell et al., 1989; Vázquez-Borsetti et al., 2011; Rojas-Piloni et al., 2017), while 
others found the opposite (Pinto and Sesack, 2000; Gabbott et al., 2005; Morishima and Kawaguchi, 2006; Kim et al., 2017; Otis et al., 2017; Cruz et al., 2021). Therefore, we carried out two independent experimental approaches to clarify this issue (Fig. 4).
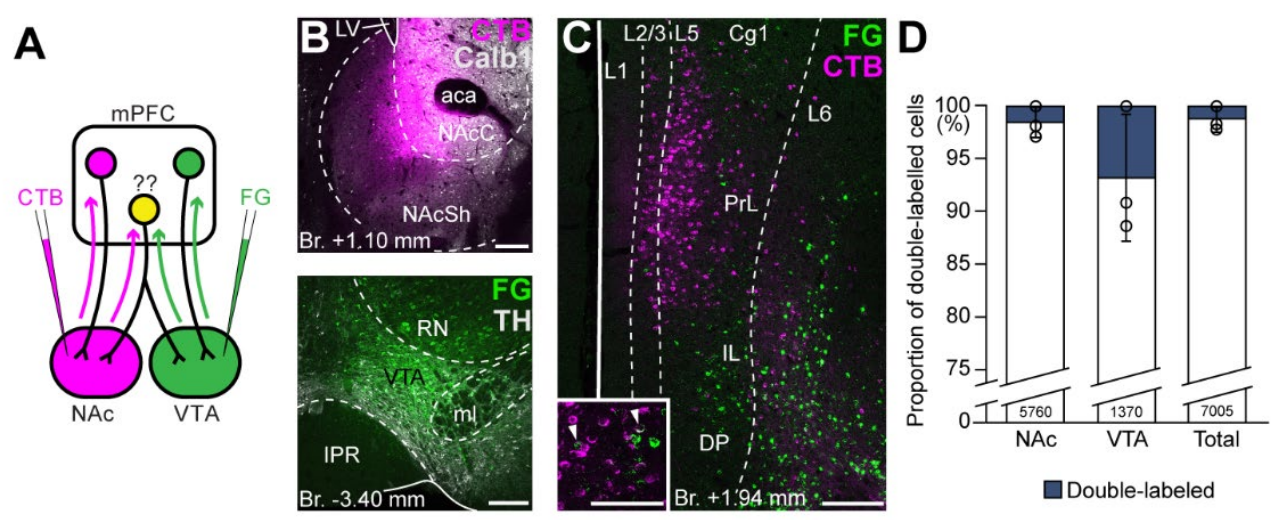

Figure 4. VTA and NAc are mostly innervated by non-overlapping mPFC cell populations. A, Experimental design of double retrograde tracing experiments. $B$, Representative CTB (magenta) injection site in the NAC (top) and FG (green) in the VTA (bottom). C, High magnification confocal image showing the distribution of $M_{P F C_{N A C}}$ (magenta) and MPFC $V$ TA cells (green) in the MPFC. Inset shows higher magnification of the same slice with arrowheads representing double-labelled cells. D, Only a small proportion of labelled mPFC cells innervated both VTA and NAC. Scale bars: $200 \mu \mathrm{m}, \mathrm{C}$ inset: $100 \mu \mathrm{m}$. aca, anterior commissure, anterior part; IPR, interpeduncular nucleus, rostral subnucleus; $L V$, lateral ventricle; $m l$, medial lemniscus; $R N$, red nucleus. Data are shown as mean $\pm S D$.

First, we performed double retrograde tracings with FG and CTB (interchangeably) from the NAc and the VTA (Fig. 4A-B) and investigated the overlap of the labelled populations in the mPFC (Fig. 4C). Our results showed that only a small proportion of all cells contained both tracers (NAc+VTA/VTA $=6.78 \pm 5.97 \%$, NAc+VTA/NAc $=1.54 \pm 1.40 \%$, NAc + VTA/total $=1.26 \pm 1.12 \% ; N_{N A c}=269,2940,2551$ cells, $N_{V T A}=111$, 489, 770 cells, $N_{V T A+N A C}=0,55,70$ cells; $n=3$ mice; Fig. $4 D$; Table 3 ) and most of them were found in the L5.

Although these results indicate that $\mathrm{MPFC}_{\mathrm{NAc}}$ and $\mathrm{mPFC} \mathrm{VTA}_{\mathrm{VA}}$ populations are mostly nonoverlapping at the cellular level, we considered that double retrograde technique tends to underestimate the actual proportion of multiple projecting cells. Therefore, we also applied an intersectional viral tracing approach to clarify the target selectivity of mPFC neurons. We injected Canine adenovirus type 2 carrying Cre-recombinase gene (CAV2-Cre) into the NAc or VTA, and Cre-dependent AAV-DIO-mCherry into the MPFC (Fig. $5 A-C$ ), a technique that was previously shown to be suitable to label cortico-tegmental and cortico-accumbal pathways (Beier et al., 2015; Kerstetter et al., 2016; Kim et al., 2017; Cruz et al., 2021). Using this method, we could selectively label $\mathrm{mPFC}_{\text {NAC }}$ and mPFC $\mathrm{VTA}_{\mathrm{V}}$ neurons 
with their entire axonal arborization, including collaterals projecting to other brain regions. After confirming that the injection sites were correctly positioned in the NAc or VTA (see Methods, Fig. 5B1, C1) and in the mPFC (Fig. 5B2, C2), we compared the projection pattern of $\mathrm{PPFC}_{\mathrm{NAc}}$ and $\mathrm{mPFC}$ VTA neurons both in the NAc and the VTA (Fig. 5D-E). We found that $\mathrm{PPFC}_{\mathrm{NAc}}$ axons were abundant in the NAc (Fig. 5D, left), while only a few labelled axons were present in the VTA (Fig. 5D, right). Conversely, mPFC $_{V T A}$ neurons sent only sparse innervation to the NAc (Fig. $5 E$, left), but we found dense innervation in the VTA (Fig. 5E, right).
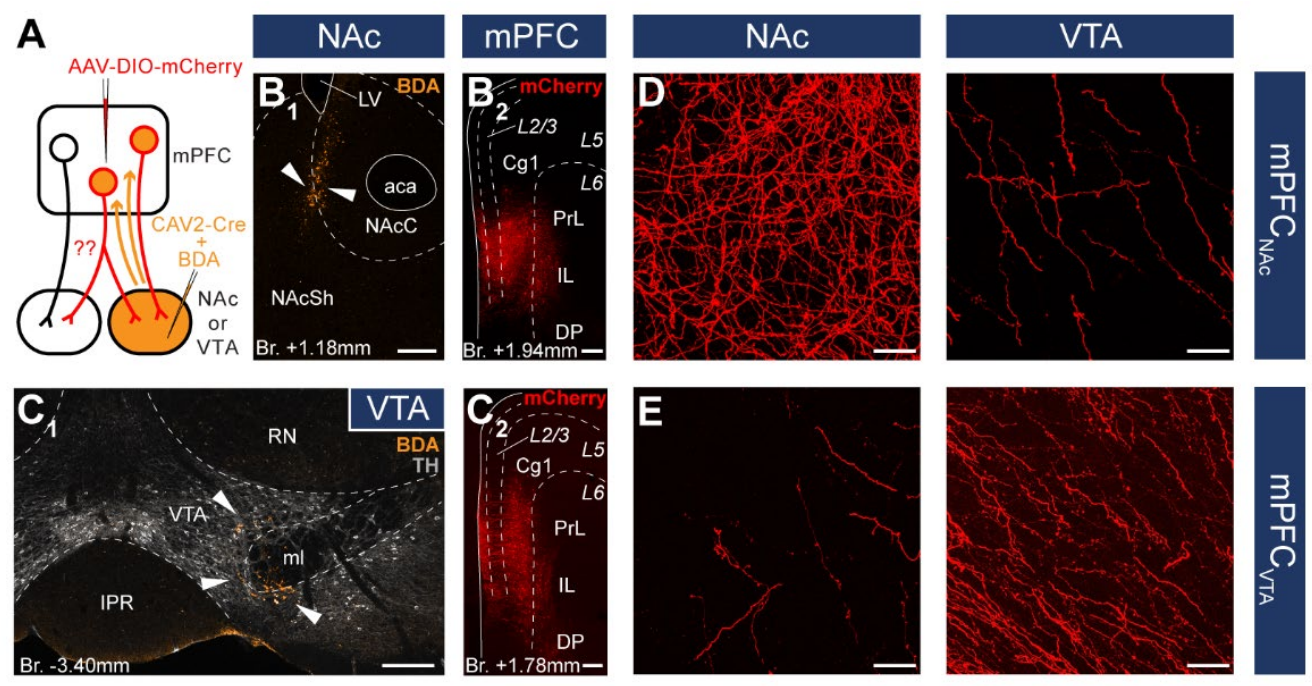

H
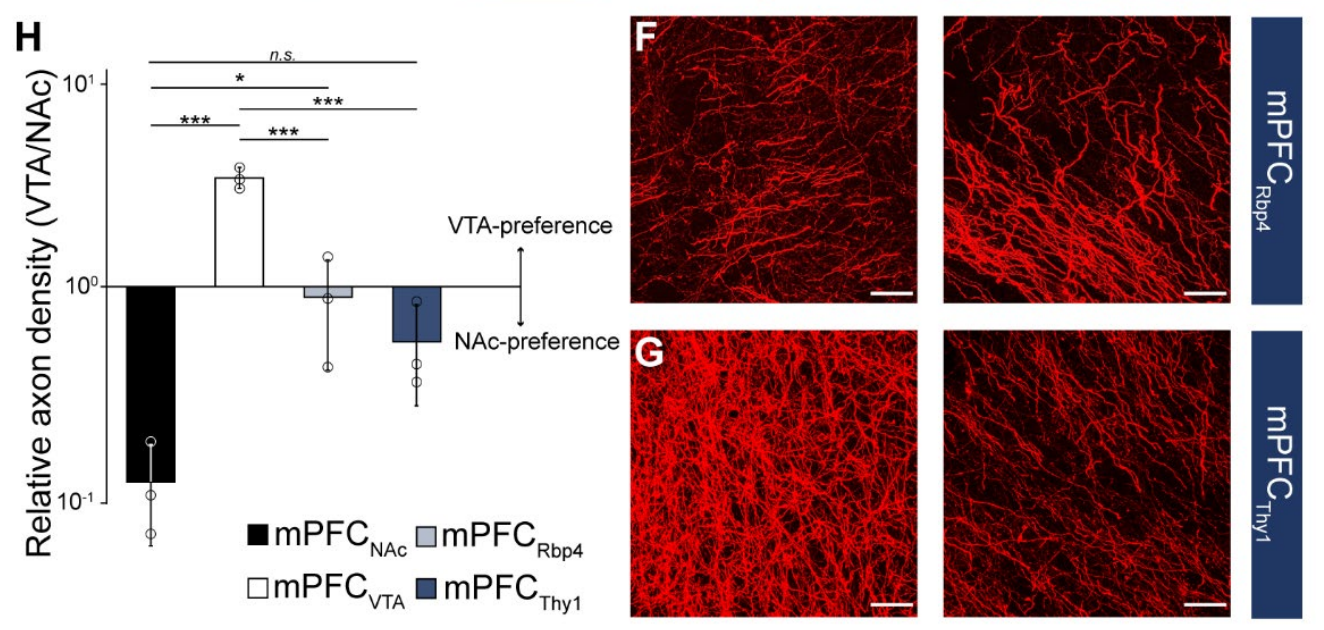

Figure 5. NAC- or VTA-preference of MPFC cells. A, Experimental design of CAV2-Cre mediated viral tracing experiments. BDA was used to visualize the exact location of injection sites. $B$, Representative CAV2-Cre $+5 \%$ BDA (orange) injection site (B1) in the NAc and AAV-DIO-mCherry (red) injection site (B2) in the mPFC of the same animal. $C$, Representative CAV2-Cre+BDA (green) injection site (C1) in the VTA counterstained with TH (grayscale) and AAV-DIO-mCherry (red) injection site (C2) in the MPFC of the same animal. D-G, High magnification confocal images showing the distribution of mCherry (red) labelled axons in the NAC (left) and the VTA (right) in a mPFC (D), MPFCVTA (E), MPFC Rbp4 (F; same animal as in Fig. 3C, H, M and Fig. 3-1B) and mPFC Thy1 (G; same animal as in Fig. $3 F, K, P$ and Fig. 3-1E) animal. $\boldsymbol{H}$, Quantification of relative axon density (RAD) in the $m P F C_{N A C}, m P F C_{V T A}, m P F C_{R b p 4}$ 
and $m P F C_{\text {Thy } 1}$ animals. ${ }^{*} p<0.05 ;{ }^{* *} p<0.001$. Scale bars: $\boldsymbol{B}-\boldsymbol{C}, 200 \mu \mathrm{m}, \boldsymbol{D}-\mathbf{G}, 20 \mu \mathrm{m}$. aca, anterior commissure, anterior part; $B D A$, biotinylated dextran amine; IPR, interpeduncular nucleus, rostral subnucleus; $L V$, lateral ventricle; $m l$, medial lemniscus; $R N$, red nucleus. Data are shown as mean $\pm S D$.

To quantify these results, we applied high magnification confocal imaging (63x) to measure and compare the relative axon densities (RAD) in the two target areas. This quantitative analysis showed that $\mathrm{mPFC}_{\mathrm{NAC}}$ neurons innervated the NAc almost ten-fold stronger than the VTA $\left(\operatorname{RAD}_{(\mathrm{VTA} / \mathrm{NAc})}=0.11 \pm\right.$ 0.06; $n=3$ animals; Fig. $5 H$; Table 4). On the other hand, mPFC $\mathrm{VTA}_{\mathrm{A}}$ cells innervated preferentially the VTA as opposed to the $\operatorname{NAc}\left(\operatorname{RAD}_{(\mathrm{VTA} / \mathrm{NAc})}=3.45 \pm 0.41 ; n=3\right.$ animals; Fig. $5 H$; Table 4).

As controls, we used Rbp4- (mPFC $\left.\mathrm{Rbp}_{4}\right)$ and Thy1-Cre (mPFC Thy1 $_{1}$ ) animals from the previous viral tracing experiments (Fig. 4), since these two cell populations innervated both the NAC and VTA intensively (Fig. $5 F-G$ ). Our analysis revealed that $\mathrm{MPFC}_{\mathrm{Rbp} 4}$ cells innervated both regions similarly $\left(\operatorname{RAD}_{\text {(VTA/NAc) }}=0.88 \pm 0.49 ; n=3\right.$ animals; Fig. $5 F, H$; Table 4), while mPFC Thy $1_{1}$ cells tended to innervate NAc slightly more intensively $\left(\operatorname{RAD}_{(\mathrm{VTA} / \mathrm{NAc})}=0.53 \pm 0.28 ; n=3\right.$ animals; Fig. $5 G-H$; Table 4). One-way ANOVA analysis revealed significant differences between groups $\left(\mathrm{F}_{(3,8)}=55.56 ; p=0.000011 ; \mathrm{mPFC}_{\mathrm{NAc}}\right.$ Vs

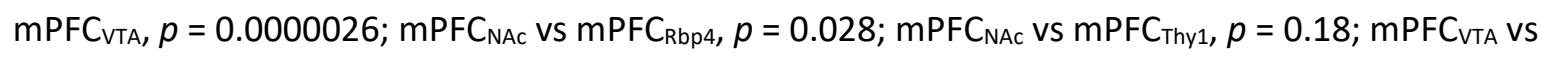
$\mathrm{mPFC}_{\mathrm{Rbp} 4}, p=0.000018 ; \mathrm{mPFC}_{\mathrm{VTA}}$ Vs mPFC $\mathrm{m}_{\text {Thy } 1}, p=0.0000072$; LSD post-hoc test; Fig. $5 H$ ). These and the double retrograde tracing results indicate that $\mathrm{MPFC}_{\mathrm{NAc}}$ and $\mathrm{mPFC} \mathrm{VTA}_{\mathrm{A}}$ neurons are rather nonoverlapping, although there is a marginal population - in the L5 - that innervates both areas.

\section{$\mathrm{MPFC}_{\mathrm{NAc}}$ and $\mathrm{mPFC}$ VTA populations have different efferent connections}

After confirming that $\mathrm{MPFC}_{\mathrm{NAC}}$ and $\mathrm{mPFC} \mathrm{VTA}_{\mathrm{A}}$ neurons are mostly separated at the cellular level, we sought to investigate the projection pattern of these populations throughout the brain. Therefore, we used immunoperoxidase development with DAB-Ni as a chromogen ( $\left.\mathrm{IHC}_{\mathrm{DAB}-\mathrm{Ni}}\right)$ (Fig. 3-1) for the $\operatorname{mPFC}_{\text {NAC }}\left(n=3\right.$ mice) and mPFC ${ }_{V T A}(n=3$ mice) brain samples. Semi-quantitative investigation of the samples revealed clear differences between the two populations (Fig. 6; Table 5). Most notably, mPFC $\mathrm{NAc}$ neurons projected intensively to the ipsi- and contralateral striatum - including the NAC (Fig. 6C, left) -, various cortical areas (Fig. 6A-H, left), and the amygdala (Fig. 6F, left). On the other hand, mPFC $\mathrm{VTA}_{\mathrm{A}}$ innervation was strongest in the lateral (LS) and medial septum (MS; Fig. 6C, right), the hypothalamus $(\mathrm{HT})$, the bed nucleus of the stria terminalis (BNST; Fig. 6D-F, right), the midline thalamic nuclei (Fig. 6EF), the zona incerta (Zl; Fig. 6F, right) and various tectal (Fig. 6G-H, right), tegmental - including the VTA 
- (Fig. 6G-I, right) and pontine regions (Fig. 6G-I, right). Taken together, our investigation revealed that mPFC $_{\text {NAc }}$ and mPFC $V$ VTA populations differ in their projection patterns not only in the NAc and VTA, but throughout the brain.

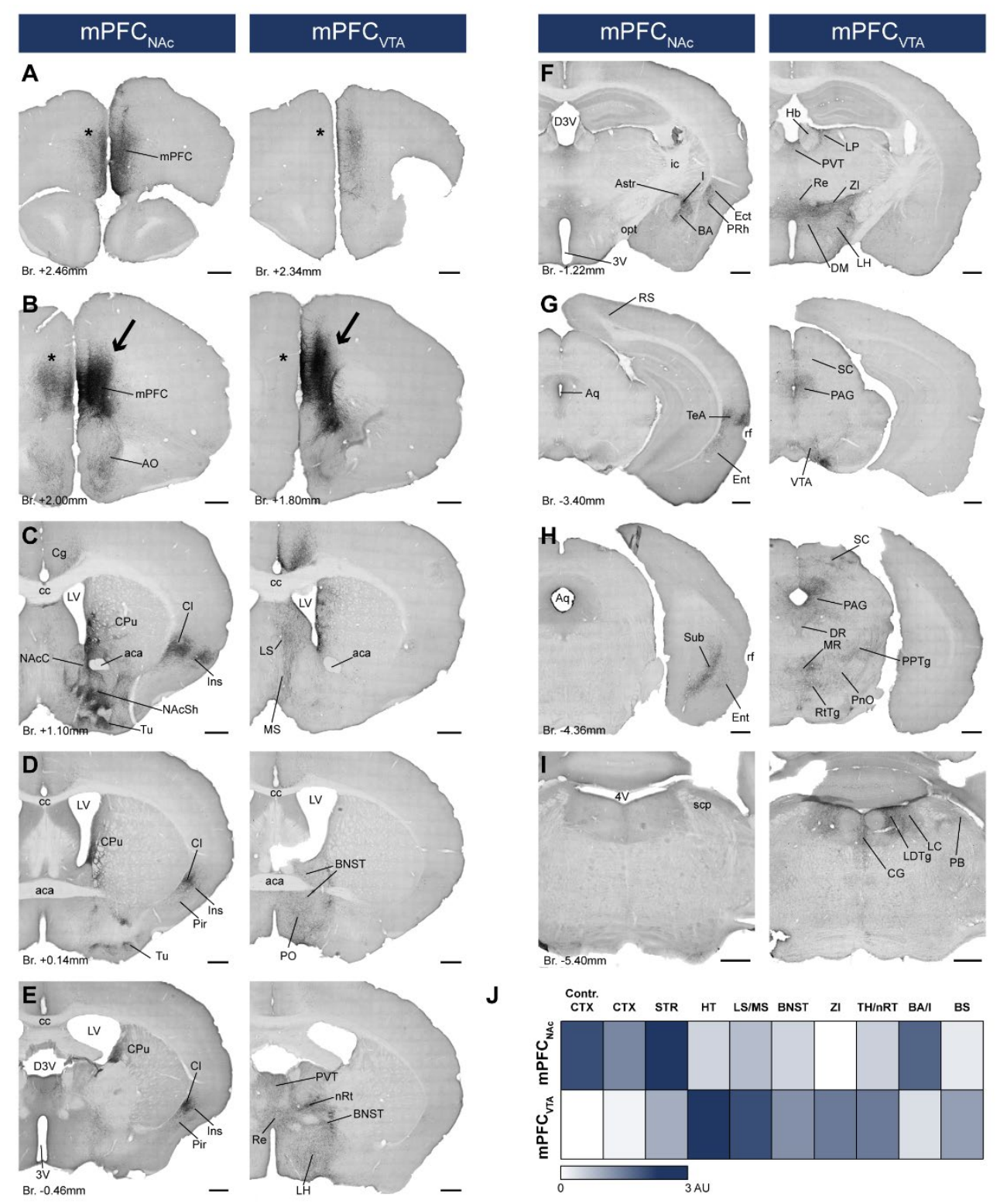

Figure 6. $M P F C_{N A C}$ and $m P F C_{V T A}$ neurons possess different efferent connections. A-I, Brightfield images showing the distribution AAV-DIO-mCherry labelled axons visualized with IHC $C_{D A-N i}$ at different AP levels. Arrows indicate AAV injection sites in the MPFC (B). Note the clear difference between the mPFC $C_{N A C}$ (left column) and mPFCVTA (right column) populations, most prominently in the striatum (C), different cortical areas (A-H), the hypothalamus (D-F) and the brainstem (F-I) - including the VTA (G). Note the almost complete lack of contralateral cortical projection in mPFC VTA animals as opposed to MPFC $C_{N A C}$ animals (A-B, asterisks). For experimental design see Fig. 6A. J, Summary table showing the innervation intensities of $M P F C_{N A C}$ (top row) and MPFC $V T A$ (bottom row) populations in different brain regions. Darker color indicates stronger innervation. Scale bars: $500 \mu \mathrm{m}$. 3V, 3rd ventricle; $4 \mathrm{~V}$, 4 th ventricle; aca, anterior commissure, anterior part; $A O$, anterior olfactory nucleus; Astr, amygdalostriatal transition area; Aq, 
aqueduct; $B A$, basolateral amygdaloid nucleus; BNST, bed nucleus of the stria terminalis; BS, brainstem; $c c$, corpus callosum; CG, central gray; CPu, caudate putamen; CTX, cortex; D3V, dorsal 3rd ventricle; DM, dorsomedial hypothalamic nucleus; DR, dorsal raphe; Ect, ectorhinal cortex; Ent, entorhinal cortex; Hb, habenula; I, intercalated amygdalar nuclei; ic, internal capsule; Ins, insular cortex; LH, lateral hypothalamus; LC, locus coeruleus; LDTg, laterodorsal tegmental nucleus; $L P$, lateral posterior thalamic nucleus; $L S$, lateral septum; $L V$, lateral ventricle; $M R$, medial raphe; MS, medial septum; $n R T$, reticular thalamic nucleus; $P V T$, paraventricular thalamic nucleus; VDB, nucleus of the vertical limb of the diagonal band; VP, ventral pallidum; opt, optic tract; PAG, periaqueductal gray; PB, parabrachial nucleus; Pir, piriform cortex; PnO, pontine reticular nucleus, oral part; PO, preoptic area; PPTg, pedunculopontine tegmental nucleus; $P R h$, perirhinal cortex; Re, reuniens thalamic nucleus; $r f$, rhinal fissure; $R S$, retrosplenial cortex; RtTg, reticulotegmental nucleus of the pons; SC, superior colliculus; scp, superior cerebellar peduncle; STR, striatum; Sub, subiculum; TeA, termporal association cortex; TH, thalamus; Tu, olfactory tubercule; ZI, zona incerta.

\section{Discussion}

Here we described the molecular, neurochemical, and anatomical characteristics of mPFC neurons innervating the mesocorticolimbic system. We found that most mPFC neurons projecting to the NAc and the VTA were localized in the same subregions, but in different layers. Accordingly, mPFC $_{\mathrm{NAc}}$ and MPFC $_{V T A}$ neuron populations showed minimal overlap at the cellular level, expressed different combination of layer-specific molecular markers and their efferent connections showed clear differences throughout the brain. While $\mathrm{mPFC}_{\mathrm{NAc}}$ neurons mostly innervated ipsi- and contralateral cortical, striatal and amygdalar regions, mPFC $\mathrm{VTA}_{\mathrm{A}}$ axons were most abundant in various ipsilateral diencephalic and mesencephalic areas.

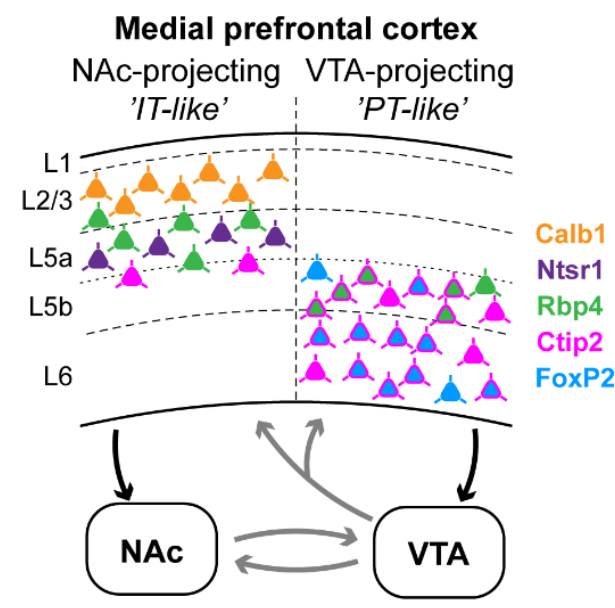

Figure 7. Summary: molecular characteristics and laminar distribution of the two identified projection groups in the MPFC. Neurons that innervate the NAC ('IT-like') are mostly localized in the upper layers of the mPFC (L2/3-5a) and express Calb1 (green), Ntsr1 (purple), Rbp4 (orange) and, to a lesser extent, Ctip2 (magenta). mPFC cells that innervate the VTA ('PT-like') are mostly localized in the deeper layers (L5b-6) and express Ctip2, FoxP2 (cyan) and Rbp4. Connections between NAc and VTA, and ascending VTA pathways (gray arrows) are based on literature data (see Introduction, Discussion). 
Generally, $\mathrm{mPFC}_{\mathrm{NAc}}$ and $\mathrm{mPFC} \mathrm{VTA}_{\mathrm{VA}}$ neurons were found in the same subregions, namely the PL, IL, MO, Cg1, DP and DTT, confirming previous results (Gabbott et al., 2005). However, one notable difference emerged between the two populations. While $\mathrm{mPFC}_{\mathrm{NAC}}$ neurons formed one, mostly continuous cluster with the highest number of cells in the PL, IL, and MO, mPFC $\mathrm{VTA}_{\mathrm{TA}}$ neurons formed two visually distinct laminar clusters: one in the middle and another in the deeper part of the mPFC.

Regarding their laminar distribution, $\mathrm{MPFC}_{\mathrm{NAc}}$ neurons were mostly found in the superficial layers (L2/3 and L5a), as previously reported (Kim et al., 2017). Traditionally, most striatum-projecting cortical neurons belong to the IT projection group (Harris and Shepherd, 2015). High ratio of Calb1 expressing neurons in the $L 2 / 3$ ( 70\%) and strong innervation of the NAc in the Calb1-Cre animals also suggest their IT-like nature, since Calb1 is considered to be an IT-marker (Harris et al., 2019). The functional importance of these L2/3 mPFC cells has been shown by Shrestha and colleagues (2015) demonstrating that their genetic perturbation leads to augmented depressive behavior in response to stressful events, possibly via the NAc-hypothalamic pathway.

In addition to Calb1, Rbp4 - a genetic marker for both IT and PT neurons (Rojas-Piloni et al., 2017; Harris et al., 2019) -, was also expressed to some extent in the L2/3 besides the L5 of the mPFC. Accordingly, these cells provided strong input to NAc. Surprisingly, despite their relatively low number, mPFC neurons expressing Ntsr1, distributed only in the L5a, also heavily innervated the NAc. These observations indicate regional differences in the distribution of the Rbp4 and Ntsr1-expressing cortical neurons, since Rbp4 is known to be present in the L5, while Ntsr1 is a generally used marker for L6 CT neurons in other, mostly primary cortical regions (Jeong et al., 2016; Sundberg et al., 2018; Matho et al., 2021). We confirmed these results using the same viral tracing experimental approach and the same animal strains targeting the neighboring primary motor cortex to exclude the possibility of a faulty mouse/viral strain. In fact, Rbp4 cells were exclusively localized in the L5 of M1. Furthermore, Ntsr1 neurons were only distributed in the L6 of the M1 and innervated the thalamus but not the striatum (data not shown). These results indicate that some molecular markers have distinct laminar distribution and projection patterns in primary and higher order cortical areas.

Further supporting this notion, we demonstrated that Ctip2, which is generally present in PT neurons of the L5b-L6 (Arlotta et al., 2005; Ueta et al., 2014; Kim et al., 2017) was expressed in about one-fifth of all mPFC $\mathrm{NAc}_{\mathrm{N}}$ (IT-like) neurons. This suggests that either some PT-like mPFC neurons innervate the striatum or, alternatively, some IT-like neurons express Ctip2 in the MPFC. Previous results reported 
that PT neurons in the motor cortex can weakly innervate the striatum (Economo et al., 2018; Matho et al., 2021) supporting the first option. However, to the best of our knowledge, there is no direct evidence for the complete absence of Ctip2-expression in IT neurons, so we cannot completely rule out the second possibility either.

While $\mathrm{mPFC}_{\mathrm{NAC}}$ neurons were present rather superficially, $\mathrm{MPFC}_{\mathrm{VTA}}$ neurons were mostly localized in the deeper layers, namely in L5b and L6 (Geisler and Zahm, 2005) and the vast majority ( 95\%) of them expressed Ctip2. Furthermore, Rbp4 neurons - shown to have reinforcing effect (Pan et al., 2021) - innervated the VTA and the NAc with a similar intensity. If we assume that IT- and PT-like Rbp4 neurons are spatially separated (in L2/3-L5a and L5b, respectively), and that IT-like neurons innervate the NAc but not the VTA, then, these results suggest that mPFC ${ }_{V T A}$ neurons have a PT-like phenotype. However, FoxP2, a L6 CT neuron marker (Kast et al., 2019; Matho et al., 2021) was also expressed by almost half of all mPFC $\mathrm{VTA}_{\mathrm{A}}$ cells. This observation was confirmed by cell-specific viral tracing in the FoxP2-Cre mouse strain, where labelled neurons were found in the $\mathrm{L} 6$ and projected heavily to the VTA and to the thalamus (data not shown), resembling a mixed PT-CT population. Accordingly, axons of the CAV2-Cre-labelled mPFC $\mathrm{VTA}_{\mathrm{A}}$ neurons collateralized to the thalamus as well. In contrast, FoxP2 neurons in the M1 cortex showed clear CT phenotype (data not shown), as it was previously reported (Matho et al., 2021). These results strengthened our previous assumption that some cell-types have different anatomical phenotype in primary and prefrontal cortical regions.

The different laminar distribution and molecular characteristics of $\mathrm{MPFC}_{\mathrm{NAc}}$ and $\mathrm{mPFC} \mathrm{VTA}_{\mathrm{A}}$ neurons suggest that these populations are mostly separated. However, previous publications yielded contradictory results about the target-selectivity of $\mathrm{MPFC}$ neurons, which can be resolved, if we consider that multiple projection was found to be high when the experiments were carried out in one neuron population (e.g., only IT or only PT neurons) (Thierry et al., 1983; Ferino et al., 1987; Cassell et al., 1989; Vázquez-Borsetti et al., 2011; Rojas-Piloni et al., 2017), but low when the experiments involved mixed populations (e.g., PT and IT neurons) (Pinto and Sesack, 2000; Gabbott et al., 2005; Morishima and Kawaguchi, 2006; Kim et al., 2017; Otis et al., 2017; Cruz et al., 2021). Gao et al. (2020) found relatively high overlap between NAc- (IT) and VTA (PT) projecting neurons in the Cg1, however, examining only a relatively small sample size. Recent publications (Callaway et al., 2021; Muñoz-Castañeda et al., 2021; Peng et al., 2021) showing extensive collateralization of fully reconstructed IT and PT neurons also suggest that cortical pyramidal neurons have a multiple-projecting nature. Collectively, these results imply that a single mPFC neuron is not target-selective, but target-preference can be identified at class, 
or subclass level. We directly tested this and found that retrogradely labelled $\mathrm{mPFC}$ Nac and $\mathrm{mPFC} \mathrm{VTA}_{\mathrm{A}}$ neurons showed minimal overlap $(<2 \%)$, indeed. Furthermore, using CAV2-Cre-mediated viral tracing we demonstrated that $\mathrm{MPFC}_{\mathrm{NAC}}$ cells innervate the NAc approximately ten times stronger than the VTA. On the other hand, mPFC VTA neurons also showed clear preference (3.5-fold) for the VTA over the NAc. Considering that mPFC innervates the VTA with a relatively sparse axon-arborization (Carr and Sesack, 2000; Geisler and Zahm, 2005), these result further support that these populations are rather nonoverlapping at the single-cell level. Complete projection pattern analysis revealed that these populations tend to innervate different areas throughout the brain. Specifically, $\mathrm{mPFC}_{\mathrm{NAC}}$ neurons showed IT-like projection pattern (mainly ipsi- and contralateral cortical, amygdalar and striatal targets), while mPFC $\mathrm{VTA}_{\mathrm{A}}$ efferents resembled PT neurons (mainly ipsilateral mesencephalic and diencephalic targets).

In general, $\mathrm{mPFC}_{\mathrm{NAC}}$ neurons participate in a range of reward-related tasks. For example, activation of $\mathrm{mPFC}_{\mathrm{NAC}}$ neurons suppresses reward seeking in a conflicting situation (Kim et al., 2017). On the other hand, others reported that optical stimulation of $\mathrm{MPFC}_{\mathrm{NAc}}$ neurons promote conditioned reward seeking (Otis et al., 2017). In accordance, Britt et al. (2012) demonstrated that optical stimulation of mPFC terminals in the NAc can facilitate self-stimulation, although Stuber and colleagues (2011) reported the lack of such effect. Therefore, it seems plausible that there is a topographical segregation within the mPFC-to-NAc pathway with different functional properties or different cell-types conveying different behavioral information, or the combination of both. Similarly, it was previously reported that MPFC neurons can excite and inhibit VTA dopamine neurons equally (Lodge, 2011), which also suggests functional separation within the mesocorticolimbic system. Recent findings of topographically biased input-output connectivity of different mPFC (Cruz et al., 2021) and VTA dopamine neurons (Aransay et al., 2015; Beier et al., 2015), as well as high topographic precision in corticostriatal pathways (Hooks et al., 2018) further support this suggestion. So, cell-specific studies are needed to completely clarify the functional complexity of these pathways.

Taken together, $\mathrm{mPFC}_{\mathrm{NAc}}$ and $\mathrm{mPFC} \mathrm{VTA}_{\mathrm{V}}$ populations are rather non-overlapping and their afferent connectivity shows IT- and PT-like features, respectively. However, high CT marker (FoxP2) expression in mPFC $_{\text {VTA }}$ neurons, as well as PT (Ctip2) and CT (Ntsr1) marker expression in PFC $_{\text {NAc }}$ neurons indicate that the traditional IT-PT-CT classification is less evident in the mPFC. In accordance, recent publications also demonstrated high genetic diversity of cortical neurons (Bakken et al., 2021; Callaway et al., 2021; Matho et al., 2021; Zhang et al., 2021), even within projection neuron classes in primary cortices. Therefore, in the future, understanding the versatility of prefrontal cortical influence over 
mesocorticolimbic functions requires a combination of molecular-, cellular-, laminar- and region-specific approaches.

\section{Anatomical considerations}

It is generally accepted that the rodent MPFC is anatomically homologous to the primate anterior cingulate cortex (Russo and Nestler, 2013; Vogt and Paxinos, 2014). However, there are notable nomenclatural inconsistencies (Laubach et al., 2018; Le Merre et al., 2021) in the rodent mPFC literature (Lodge, 2011; Bossert et al., 2012; Adhikari et al., 2015; Shrestha et al., 2015; Warren et al., 2019; Lichtenberg et al., 2021). For example, the exact definition of the PrL subregions greatly varies between publications, just like the distinction between dorsal and ventral mPFC. Such inaccuracies can contribute to the still abundant contradictions in the literature and complicate the proper interpretation of the results.

To overcome these setbacks, we combined multiple $\mathrm{IHC}_{\text {Fluo }}$ against different molecular markers that can (1) delineate the borders between different subregions (PV, Calb1) (van Brederode et al., 1991; Sun et al., 2002; Akhter et al., 2014; Mátyás et al., 2014) and (2) clearly define cortical layers in the mPFC (Calb1, Ctip2, FoxP2) (Ferland et al., 2003; Kim et al., 2017). We always used these markers to locate injection sites and labelled neurons within the mPFC. Reliable primary antibodies raised in several different species against all of these markers are commercially available and they can be combined easily. Therefore, we suggest the general adoption of this method to precisely define and separate mPFC subregions and layers in future studies.

Conflict of Interest Statement: The authors declare no competing interests.

Acknowledgements: The authors thank Tamás Herczeg, Réka Erdős, Anna Fehér and Dóra Zsíros for laboratory assistance, the Institute of Enzymology of the Research Centre for Natural Sciences for the confocal microscope, Dóra Zelena for the CAV2-Cre virus, Norbert Hájos for providing antibodies and László Acsády, Péter Barthó and Balázs Rózsa for the Cre animals. We also thank Norbert Hájos for comments and discussions about the manuscript. This work was supported by the Ministry of Innovation and Technology of Hungary from the National Research, Development and Innovation Fund (FK124434, K138836 and KKP126998 to F.M), by the Hungarian Brain Research Program (2017-1.2.1-NKP-201700002 to F.M.) by the New National Excellence Program of the Ministry for Innovation and Technology (ÚNKP-21-5-ÁTE-2 to F.M.; ÚNKP-18-3-II-BME-55, ÚNKP-20-3-II-BME-24 and ÚNKP-21-3-II-BME-61 to Á.B.). F.M. is a János Bolyai Research Fellow. 


\section{Materials and Methods}

Animals

Adult (3-5 months old, male and female) wild-type, Rbp4-Cre (Tg(Rbp4-cre)KL100Gsat, RRID: MMRRC_037128-UCD, gift from L. Acsády), Thy1-Cre (FVB/N-Tg(Thy1-cre)1VIn/J, RRID:

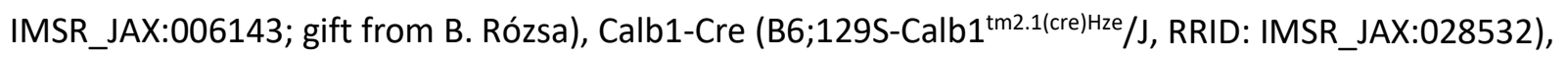
Ntsr1-Cre (Tg(Ntsr1-cre)GN220Gsat, RRID: MMRRC_017266-UCD a gift from P. Barthó) and FoxP2-Cre

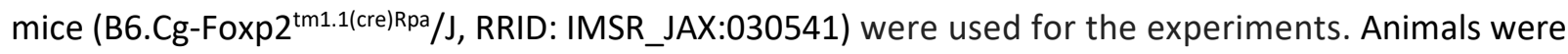
group housed in a humidity- and temperature-controlled environment. Animals were entrained to a 12 h light/dark cycle (light phase from 07:00 AM) with food and water available ad libitum. All procedures were approved by the Regional and Institutional Committee of the Research Centre for Natural Sciences.

\section{Stereotactic surgeries}

Classical retrograde tracing. All animals were anesthetized under ketamine-xylazine $(5: 1,3 x$ dilution, ketamine: $100 \mathrm{mg} / \mathrm{kg}$; xylazine: $4 \mathrm{mg} / \mathrm{kg}$ ) during all anatomical surgeries. Single and double retrograde tracing surgeries were carried out with $0.5 \%$ Cholera Toxin B subunit (CTB; List Biological Laboratories: 104) and/or 2\% Fluoro-Gold (FG; Fluorochrome LLC) to reveal the prefrontal cortical source of NAc (AP/L/DV: +1.4/ $\pm 0.8 / 3.9-4.2$ ) and VTA (AP/L/DV: -3.3/ $\pm 0.3 / 4.0-4.2)$ innervation. Tracers were iontophoretically injected (7-7 sec on/off duty cycle, 3-5 $\mu \mathrm{A}$, for 5-10 min) with IonFlow Bipolar electrophoretic equipment (Supertech Instruments Hungary). After all surgeries, animals received Rimadyl (Carprofen, $1.4 \mathrm{mg} / \mathrm{kg}$ ).

For anatomical analysis, after 7 days of survival time, mice were perfused transcardially first with saline ( $\sim 50 \mathrm{ml})$, then, with $\sim 150 \mathrm{ml}$ of fixative solution containing $4 \%$ paraformaldehyde (Sigma) in $0.1 \mathrm{M}$ phosphate buffer (PB). Animals in which the injections sites or tracer tracks reached regions that could affect labelling (e.g.: caudate putamen, substantia nigra, ventral pallidum) were excluded from further analysis.

Identification of different brain regions and cortical layers. We used different neurochemical markers to identify brain regions of interest and to separate cortical layers in the tissue samples labelled with fluorescent immunohistochemistry ( $\mathrm{IHC}_{\mathrm{Fluo}}$ ). Calbindin (Calb1) staining (see below) was used to delineate the core (strong Calb1 expression) and shell (weak Calb1 expression) region of the NAC (Jongen-Rêlo et al., 1994), and tyrosine hydroxylase (TH) staining for the VTA (Oades and Halliday, 1987; Morales and Margolis, 2017). Layer 2/3 (L2/3) of the cerebral cortex was identified using Calb1 staining 
(van Brederode et al., 1991; Sun et al., 2002), while L6 with forkhead box protein P2 (FoxP2) staining (Ferland et al., 2003). COUP-TF-interacting protein 2 (Ctip2) staining was used to label L5b and L6 (DeNardo et al., 2015) (Fig. 1-1).

We used the 2nd Edition of the Mouse Brain is Stereotaxic Coordinates by Paxinos and Franklin (2001) as a reference, because the vast majority of mPFC literature uses this nomenclature. In comparison with the newest, 5th edition (Franklin and Paxinos, 2019), the mPFC region we defined as prelimbic cortex ( $\mathrm{PrL}$ ) is approximately equivalent to the $\mathrm{A} 32$ area, the infralimbic cortex (IL) to the A25, and the rostral aspects of the cingulate cortex, area 1 and 2 (Cg1-2) to the A24b and A24a, respectively. The secondary motor (M2), medial orbital (MO), dorsal peduncular cortex (DP) and dorsal tenia tecta (DTT) regions have not changed significantly between the two editions.

Anterograde viral tracing. For cell type-specific anterograde viral tracing AAV5.EF1a.DIO.eYFP.WPRE.hGH (30-100 nl; Penn Vector Core; \#27056-AAV5; titer: 5*10 12 GC/ml) or AAV5-EF1a-DIO-mCherry viruses (30-100 nl; UNC Vector Core; \#50462; titer: 7*10 $12 \mathrm{GC} / \mathrm{ml}$ ) were injected at a rate of 0.5-1 $\mathrm{nl} / \mathrm{sec}$ into $\mathrm{mPFC}$ (AP/L/DV: $+1.7-1.9 / \pm 0.3 / 2.1-1.6 \mathrm{~mm}$ ) and M1 (AP/L/DV: $+1.4 / \pm 1.6 / 1.3-1.0 \mathrm{~mm}$ ) using a Nanoliter Injector (World Precision Instruments, FL, USA).

Animals were perfused (see above) after 4-6 weeks of survival time. Viral expression was always analyzed after IHC Fluo-enhancement (Fig. 3-1) (Falcy et al., 2020), even for eYFP (see below).

Intersectional retro-anterograde viral tracing. In order to selectively label NAc-projecting ( $\mathrm{mPFC}_{\mathrm{NAC}}$ ) and VTA-projecting mPFC cells (mPFC $\mathrm{VTA}_{\mathrm{V}}$ ), we injected Canine adenovirus type 2 carrying Crerecombinase gene (CAV2-Cre, CMV promoter, titer: $2.5^{*} 10^{10} \mathrm{pp} / \mathrm{ml}$, Plateforme de Vectorologie de Montpellier, France; a gift from D. Zelena) into the NAc ( $n=3$ animals) or VTA ( $n=3$ animals) (see coordinates above) of wild-type animals, mixed with $5 \%$ biotinylated dextrane amine (BDA, MW: 10.000, Molecular Probes: D1956, RRID: AB_2307337; 1:1; 80-120 nl/animal; 1nl/sec). Note that BDA was used to locate the tip of the injecting pipette (Fig. 5B1, C1), not the whole extent of viral diffusion. At the same time, the mPFC (see coordinates above) of the same animals was injected with AAV5-EF1a-DIOmCherry (see details above). After 6 weeks of survival, animals were perfused, and their brains were processed for further analysis (see above).

Tissue processing and immunohistochemistry

Tissue blocks were cut on a VT1200S Vibratome (Leica) into $50 \mu \mathrm{m}$ coronal sections. Freefloating sections were intensively washed with 0.1 M PB. All antibodies were diluted in 0.1 M PB. For 
fluorescent labeling, sections were first treated with a blocking solution containing $10 \%$ normal donkey serum (NDS, Sigma-Aldrich: S30-M) or 10\% normal goat serum (NGS, Vector: S-1000, RRID: AB_2336615) and $0.5 \%$ Triton-X in $0.1 \mathrm{M}$ PB for 30 minutes at room temperature (RT).

Fluorescent immunohistochemistry. Sections were incubated in primary antibody solution overnight at RT or for 2-3 days at $4^{\circ} \mathrm{C}$. The following primary antibodies were used: green fluorescent protein (GFP, chicken, Life Technology: A10262, RRID: AB_2534023; 1:2000), mCherry (mCherry; rabbit, BioVision: 5993-100, RRID: AB_1975001; 1:2000), red fluorescent protein (RFP; rat, Chromotek: 5F8, RRID: AB_2336064; 1:2000) FoxP2 (mouse, Merck Millipore: MABE415, RRID: AB_2721039; 1:2000; Invitrogen: MA5-31419, RRID: AB_2787055; 1:2000; rabbit, Abcam: ab16046, RRID: AB_2107107; 1:500), Calb1 (rabbit, SWANT: CB38, RRID: AB_10000340; 1:2000; mouse, SWANT: 300, RRID: AB_10000347; 1:2000; chicken, Synaptic Systems: 214 006, RRID: AB_2619903; 1:2000), TH (mouse, Immunostar: 22941, RRID: AB_572268; 1:8000), FG (rabbit, FluoroChrome, 1:50.000; guinea pig, Protos Biotech: NM101, RRID: AB_2314409; 1:5000), CTB (goat, List Biological Laboratories: 703; 1:20.000), parvalbumin (PV; mouse, SWANT: PV 235, RRID: AB_10000343; 1:2000) and Ctip2 (rat, Abcam: ab18465, RRID: $\left.A B \_2064130 ; 1: 500\right)$.

For $\mathrm{IHC}_{\text {Fluo }}$ staining, after primary antibody incubation, sections were treated with the following secondary IgGs (1:500; 2 hours at RT): Alexa 488-conjugated donkey anti-rabbit (DAR-A488; Jackson: 711-545-152, RRID: AB_2313584), donkey anti-mouse (Jackson: 715-545-150, RRID: AB_2340846), goat anti-chicken (Molecular Probes: A11039, RRID: AB_142924), donkey anti-guinea pig (Jackson: 706-545148, RRID: AB_2340472); Alexa 555-conjugated donkey anti-goat (Molecular Probes: A21432, RRID: AB_141788), donkey anti-mouse (Molecular Probes: A31570, RRID: AB_2536180), donkey anti-rat (Southern Biotech: 6430-32, RRID: AB_2796359); Cy3-conjugated donkey anti-rabbit (Jackson: 715-165152, RRID: AB_2307443), donkey anti-mouse (Jackson: 715-165-151, RRID: AB_2340813); Alexa 594conjugated donkey anti-mouse (Molecular Probes: A21203, RRID: AB_141633), donkey anti-rabbit (Molecular Probes: A21207, RRID: AB_141637), Alexa 647-conjugated donkey anti-mouse (Jackson: 715605-151, RRID: AB_2340863; Invitrogen: A-31571, RRID: AB_162542) or donkey anti-rabbit (Jackson: 711-605-152, RRID: AB_2492288).

When necessary, staining was enhanced after primary antibody incubation with biotinylated secondary antibodies (biotinylated horse anti-goat IgG, Vector Laboratories: BA-9500, RRID: AB_2336123; 1:300; biotinylated goat anti-rabbit - bGAR, Vector Laboratories: BA-1000, RRID: AB_2313606; 1:300; biotinylated goat anti-guinea pig, Vector Laboratories: BA-7000, RRID: AB_2336132; 
1:300; 1.5h, RT), Elite Avidin-Biotin Complex (eABC, 1:300, Vector Laboratories: PK-6100, RRID: AB_2336819; 1.5h, RT) and streptavidin conjugated fluorescent antibodies (SA-A488, Jackson: 016-540084, RRID: AB_2337249; 1:2000; SA-Cy3, Jackson: 016-160-084, RRID: AB_2337244; 1:2000; SA-A647, Jackson: 016-600-084, RRID: AB_2341101; 1:2000; 2 hrs, RT). All fluorescent slices were mounted in Vectashield (Vector Laboratories: H-1000, RRID: AB_2336789). To reveal the CAV2-Cre/BDA injection site we used eABC (see above) and SA-A488 or SA-A647 (see above).

Immunoperoxidase staining. For the whole-brain projection pattern analysis of the CAV2-Cre animals, we also performed immunoperoxidase staining and used nickel-amplified diaminobenzidine

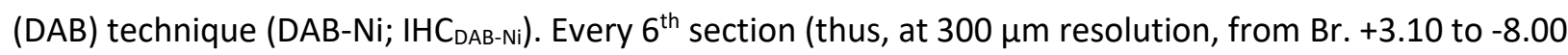
$\mathrm{mm}$ ) was treated first with $1 \% \mathrm{H}_{2} \mathrm{O}_{2}$ solution for 10 minutes, then, after intensive washing, in $10 \%$ NDS and $0.2 \%$ Triton-X solution as a blocking serum (30 mins, RT). After primary antibody incubation (mCherry, see above), slices were incubated in biotinylated secondary antibody (bGAR) and eABC (see above). Then we developed DAB-Ni for 5 minutes. Sections were then dehydrated in xylol (2*10 mins) and mounted in DePex (Serva, Heidelberg, Germany).

Viral signal amplification. To compare native mCherry expression to $\mathrm{IHC}_{\text {Fluo }}$ and $I \mathrm{HC} \mathrm{C}_{\mathrm{DAB}-\mathrm{Ni}}$ enhancement, we stained slices from the CAV2-Cre experiments with primary antibody against mCherry and DAR-A488 (see above) (Fig. 3-1A-B). Then we captured confocal images (see below) from the same brain regions in two channels (i.e., A488 and mCherry). For better visualization, we recolorized the A488 channel at Fig. 3-1A2, B2. Next, we stained the neighboring slices (i.e., $50 \mu \mathrm{m}$ apart) with IHC against mCherry (see above) and captured them with brightfield microscopy (see below) (Fig. 3-1C-D).

\section{Microscopy}

Fluorescent sections were first analyzed with epifluorescent microscope (Leica DM 2500, Leica Microsystems GmbH; Camera: Olympus DP73, CellSens Entry 1.16, Olympus Corporation) with low magnification (2.5x N PLAN 2.5x/0.07 $\infty /-/ O F N 25,5 x$ HCX FL PLAN 5x/0.12 $\infty /-/ B)$ to find injection sites and labelled cells. Higher magnification (10x Plan Apochromat 10x/0.45 M27; 20x Plan Apochromat 20x/0.8 M27, 63x Plan Apochromat 63x/1.4 Oil DIC M27) images were taken with confocal microscope (Zeiss LSM 710; Zeiss ZEN 2010B SP1 Release version 6.0; Carl Zeiss Microimaging GmbH). Brightfield imaging and whole brain projection analysis was completed with a PANORAMIC MIDI II (20x (NA 0.8); 3DHistech, Hungary) device and the manufacturer's official software (CaseViewer 2.4) for every 6th slice (i.e., at $300 \mu \mathrm{m}$ resolution). 
Colocalization. In order to reveal the proportion of FoxP2-, Ctip2- and Calb1-positive cells among retrogradely (FG/CTB) labelled $\mathrm{mPFC}_{\mathrm{NAc}}$ and $\mathrm{mPFC} \mathrm{VTA}_{\mathrm{VA}}$ cells, we captured 20x magnification confocal Zstack (step size: $5 \mu \mathrm{m}$ ) imaging of double-labelled fluorescent sections (3-4 slices/animal, $n=3-3$ animals). Labelled cells were then manually analyzed with ImageJ (NIH). Only cells visible in two separate sections with a visible nucleus were analyzed. The same protocol was used to identify doublelabelled cells in the double retrograde tracing experiments ( $n=3$ animals).

Axon density analysis. We sought to compare MPFC axon densities in the NAc and VTA in the CAV2-Cre injected mPFC ${ }_{N A c}, m_{P F C}$, and AAV5-EF1a-DIO-mCherry injected Rbp4- (mPFC $C_{R b p 4}$ ) and Thy1Cre ( $\mathrm{mPFC}_{\text {Thy1 }}$ ) samples using high-magnification (63x) confocal Z-stacks (step size: $0.27 \mu \mathrm{m}$ ). In the VTA we captured three stacks in each animal ( $n=3$ in each strain) at three different AP levels between Bregma -3.10 and $-3.80 \mathrm{~mm}$. In the NAc, we captured five-five stacks in the same animals as for the VTA at three different AP levels between Bregma $+1.00-1.80 \mathrm{~mm}$. We aimed to capture stacks where axon density was visibly the highest at each AP levels in each region.

We analyzed the confocal stacks using a custom made automatic ImageJ macro (Mátyás et al., 2018). The macro calculated the axon length for each stack and the total axon length was summated for each brain region in each animal. Then, the total axon length was compared to the summated stack volume $(\mathrm{ROI}$ area * number of slices * step size $=$ total volume) for each brain region to calculate the relative axon density (RAD = total axon length/total volume). Then, the ratio of $R A D_{V T A} / R A D_{N A C}$ $\left(\operatorname{RAD}_{(\mathrm{VTA} / \mathrm{NAC})}\right)$ was calculated for each animal, where $\operatorname{RAD}_{(\mathrm{VTA} / \mathrm{NAC})}=1$ means that the two areas are equally innervated.

\section{Statistical analysis}

Values are given as mean \pm SD in all figures. $n$ represents number of animals; $N$ represents cell counts. We used SPSS Statistics (ver. 27.0.1.0., IBM) to analyze the axon-density data. We used one-way ANOVA method with LSD post-hoc test to compare relative axon-density values after testing for the homogeneity of variances. ${ }^{*} p<0.05,{ }^{* * *} p<0.001$. 


\begin{tabular}{|c|c|c|c|c|c|c|}
\hline & \multirow{2}{*}{$\mathrm{mPFC}_{\mathrm{NAC}}$} & \multicolumn{4}{|c|}{ Layers } & \multirow[t]{2}{*}{ Total } \\
\hline & & $2 / 3$ & $5 a$ & $5 b$ & 6 & \\
\hline \multirow{3}{*}{$\frac{\overrightarrow{0}}{\overrightarrow{0}}$} & \# FG+ /animal & \multicolumn{3}{|c|}{$128,101,60$} & $287,200,168$ & $415,301,228$ \\
\hline & \# Calb1+ /animal & \multicolumn{3}{|c|}{$84,71,42$} & $7,4,7$ & $91,75,49$ \\
\hline & $\%$ Calb1+ (AVG \pm SD) & \multicolumn{3}{|c|}{$68.6 \pm 2.6 \%$} & $2.9 \pm 1.1 \%$ & $22.8 \pm 1.9 \%$ \\
\hline \multirow{3}{*}{ 恣 } & \# FG+ /animal & \multicolumn{2}{|c|}{$62,356,349$} & & $37,29,138$ & $99,385,487$ \\
\hline & \# Ctip2+ /animal & \multicolumn{2}{|l|}{$9,9,27$} & & $22,20,88$ & $31,29,115$ \\
\hline & $\%$ Ctip $2+($ AVG \pm SD) & \multicolumn{2}{|c|}{$8.26 \pm 6.01 \%$} & & $64.1 \pm 4.76 \%$ & $20.8 \pm 12.1 \%$ \\
\hline \multirow{3}{*}{$\begin{array}{l}\frac{N}{\alpha} \\
\stackrel{x}{u} \\
\dot{0}\end{array}$} & \# FG+ /animal & $288,357,173$ & \multicolumn{3}{|c|}{$20,24,0$} & $308,381,173$ \\
\hline & \# FoxP2+ /animal & $5,10,0$ & \multicolumn{3}{|c|}{$4,3,0$} & $9,13,0$ \\
\hline & $\%$ FoxP2+ (AVG \pm SD) & $1.5 \pm 1.4 \%$ & \multicolumn{3}{|r|}{$-*$} & $2.1 \pm 1.8 \%$ \\
\hline
\end{tabular}

Table 1. Proportion of FoxP2-, Ctip2- and Calb1-expressing neurons in the mPFC NAc $_{\text {population. }}{ }^{\text {When }}$ total cell count was $<10$, percentage was not calculated. \#, number of labelled cells. 


\begin{tabular}{|c|c|c|c|c|c|c|}
\hline & \multirow{2}{*}{ mPFCVTA } & \multicolumn{4}{|c|}{ Layers } & \multirow{2}{*}{ Total } \\
\hline & & $2 / 3$ & $5 a$ & $5 b$ & 6 & \\
\hline \multirow{3}{*}{$\frac{\overrightarrow{0}}{\overrightarrow{0}}$} & \# FG+ /animal & \multicolumn{3}{|c|}{$4,2,5$} & $371,452,331$ & $375,454,336$ \\
\hline & \# Calb1+ /animal & \multicolumn{3}{|l|}{$4,2,2$} & $3,2,2$ & $7,4,4$ \\
\hline & $\%$ Calb1+ (AVG \pm SD) & \multicolumn{3}{|l|}{$-*$} & $-*$ & $1.3 \pm 0.5 \%$ \\
\hline \multirow{3}{*}{ 电 } & \# FG+ /animal & \multicolumn{2}{|l|}{$1,2,1$} & \multicolumn{2}{|c|}{$152,163,187$} & $153,165,188$ \\
\hline & \# Ctip2+ /animal & \multicolumn{2}{|l|}{$1,0,0$} & \multicolumn{2}{|c|}{$144,158,178$} & $145,158,178$ \\
\hline & $\%$ Ctip2+ (AVG \pm SD) & \multicolumn{2}{|l|}{$-*$} & \multicolumn{2}{|r|}{$95.6 \pm 1.2 \%$} & $95.1 \pm 0.6 \%$ \\
\hline \multirow{3}{*}{$\begin{array}{l}\frac{N}{\alpha} \\
\frac{x}{1} \\
\dot{0}\end{array}$} & \# FG+ /animal & $162,347,411$ & \multicolumn{3}{|c|}{$393,283,275$} & $555,630,686$ \\
\hline & \# FoxP2+ /animal & $17,22,38$ & \multicolumn{3}{|c|}{$347,219,195$} & $364,241,233$ \\
\hline & $\%$ FoxP2+ (AVG \pm SD) & $8.7 \pm 2.1 \%$ & \multicolumn{3}{|c|}{$78.9 \pm 8.8 \%$} & $45.9 \pm 17.2 \%$ \\
\hline
\end{tabular}

Table 2. Proportion of FoxP2-, Ctip2- and Calb1-expressing neurons in the MPFCVTA population. * When total cell count was $<10$, percentage was not calculated. \#, number of labelled cells. 
bioRxiv preprint doi: https://doi.org/10.1101/2022.02.17.480862; this version posted February 18,2022 . The copyright holder for this preprint (which was not certified by peer review) is the author/funder. All rights reserved. No reuse allowed without permission.

\begin{tabular}{|l|c|l|l|c|}
\hline & NAc* & VTA* & Total* & Double-labelled \\
\hline \# /animal & $269,2995,2621$ & $111,544,840$ & $380,3374,3251$ & $0,55,70$ \\
\hline \% double-labelled & $1.5 \pm 1.4 \%$ & $6.8 \pm 6.0 \%$ & $1.3 \pm 1.1 \%$ & - \\
\hline
\end{tabular}

Table 3. Quantification of double retrograde tracing experiments. ${ }^{*}$ Including double-labelled cells. \#, number of labelled cells. 


\begin{tabular}{|c|c|c|c|c|c|c|c|}
\hline & & NAc & VTA & & & NAc & VTA \\
\hline \multirow{12}{*}{ 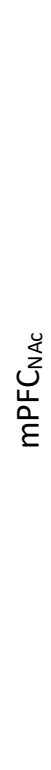 } & \multirow{3}{*}{ Axon length (mm) } & 907.58 & 30.80 & \multirow{12}{*}{ 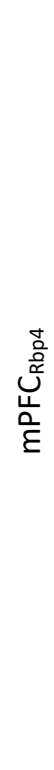 } & \multirow{3}{*}{ Axon length (mm) } & 597.27 & 299.93 \\
\hline & & 1385.42 & 24.23 & & & 617.26 & 353.48 \\
\hline & & 401.99 & 9.70 & & & 1323.86 & 99.42 \\
\hline & \multirow{3}{*}{ Volume $\left(\mathrm{mm}^{3}\right)$} & 0.018 & 0.0068 & & \multirow{3}{*}{ Volume $\left(\mathrm{mm}^{3}\right)$} & 0.019 & 0.0069 \\
\hline & & 0.020 & 0.0060 & & & 0.0089 & 0.0059 \\
\hline & & 0.019 & 0.0028 & & & 0.016 & 0.0032 \\
\hline & \multirow{3}{*}{ Density $\left(\mathrm{mm} / \mathrm{mm}^{3}\right)$} & 49215.43 & 4539.63 & & \multirow{3}{*}{ Density $\left(\mathrm{mm} / \mathrm{mm}^{3}\right)$} & 31674.39 & 43542.44 \\
\hline & & 69073.73 & 4042.84 & & & 69696.59 & 60044.90 \\
\hline & & 20991.09 & 3519.42 & & & 80501.53 & 31307.55 \\
\hline & \multirow{3}{*}{ Relative density* } & \multicolumn{2}{|c|}{0.092} & & \multirow{3}{*}{ Relative density* } & \multicolumn{2}{|c|}{1.37} \\
\hline & & \multicolumn{2}{|c|}{0.059} & & & \multicolumn{2}{|c|}{0.86} \\
\hline & & \multicolumn{2}{|c|}{0.17} & & & \multicolumn{2}{|c|}{0.39} \\
\hline \multirow{12}{*}{ 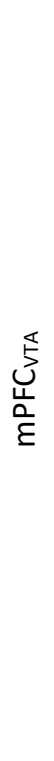 } & \multirow{3}{*}{ Axon length (mm) } & 130.72 & 196.69 & \multirow{12}{*}{ 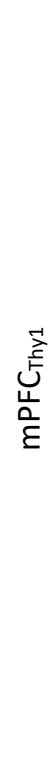 } & \multirow{3}{*}{ Axon length (mm) } & 1708.58 & 517.52 \\
\hline & & 129.94 & 161.77 & & & 2719.73 & 459.37 \\
\hline & & 46.42 & 63.91 & & & 2807.45 & 398.95 \\
\hline & & 0.017 & 0.0067 & & & 0.016 & 0.0058 \\
\hline & Volume $\left(\mathrm{mm}^{3}\right)$ & 0.016 & 0.0061 & & Volume $\left(\mathrm{mm}^{3}\right)$ & 0.016 & 0.0068 \\
\hline & & 0.014 & 0.0064 & & & 0.013 & 0.0057 \\
\hline & & 7578.49 & 29542.50 & & & 104685.07 & 88715.34 \\
\hline & Density $\left(\mathrm{mm} / \mathrm{mm}^{3}\right)$ & 7954.40 & 26648.57 & & Density $\left(\mathrm{mm} / \mathrm{mm}^{3}\right)$ & 166781.92 & 67511.08 \\
\hline & & 3206.06 & 9953.67 & & & 210241.59 & 69900.41 \\
\hline & & & & & & & \\
\hline & Relative density* & & & & Relative density* & 0. & \\
\hline & & & & & & & \\
\hline
\end{tabular}

Table 4. Quantification of axon-length and density in the VTA and NAc in the MPFC $N A c, m P F C_{V T A}, m_{P F C_{R b p 4}}$ and mPFC $C_{\text {Thy } 1}$ animals. * Relative density $=R A D_{V T A} / R_{N A c}$. 


\begin{tabular}{|c|c|c|c|c|c|c|c|}
\hline & \multicolumn{3}{|c|}{ mPFC ${ }_{V T A}$} & \multicolumn{3}{|c|}{$\mathrm{mPFC}_{\mathrm{NAC}}$} \\
\hline & & mPFC ${ }_{V T A} \# 1$ & mPFC $V_{V A} \# 2$ & mPFC ${ }_{V T A} \# 3$ & $\mathrm{mPFC}_{\mathrm{NAc}} \# 1$ & $\mathrm{mPFC}_{\mathrm{NAC}} \# 2$ & $m P F C_{N A c} \# 3$ \\
\hline \multirow{8}{*}{ CTX } & Contralat. mPFC & & & & ++ & +++ & +++ \\
\hline & Ins/Cl & + & & + & +++ & ++ & +++ \\
\hline & RS & + & & + & + & + & + \\
\hline & TeA & & & & ++ & ++ & +++ \\
\hline & Pir & & & & + & + & + \\
\hline & Ect & & & & ++ & + & ++ \\
\hline & Sub & & & & ++ & ++ & +++ \\
\hline & Ent & & & & + & ++ & ++ \\
\hline \multirow{3}{*}{ STR } & NAC & + & + & + & +++ & +++ & +++ \\
\hline & $\mathrm{CPu}$ & ++ & + & ++ & +++ & +++ & +++ \\
\hline & $\mathrm{Tu}$ & + & + & + & +++ & +++ & +++ \\
\hline \multirow{6}{*}{ TH } & PVT & +++ & +++ & +++ & ++ & + & + \\
\hline & $\mathrm{Re}$ & ++ & +++ & +++ & + & + & + \\
\hline & LP & ++ & + & ++ & + & & \\
\hline & DLG & & & + & & & \\
\hline & PIL & + & + & + & & & \\
\hline & $\mathrm{nRT}$ & ++ & ++ & +++ & + & + & + \\
\hline \multirow{5}{*}{ AMY } & $\mathrm{MeA}$ & ++ & + & ++ & + & & + \\
\hline & Astr & & & & ++ & ++ & +++ \\
\hline & $\mathrm{CeA}$ & + & & + & + & & + \\
\hline & 1 & & & + & ++ & ++ & ++ \\
\hline & $\mathrm{BA}$ & + & & + & +++ & ++ & +++ \\
\hline \multirow{20}{*}{ BS } & $\mathrm{pv}$ & +++ & ++ & +++ & + & + & + \\
\hline & PAG & +++ & ++ & +++ & + & + & + \\
\hline & VTA & +++ & +++ & +++ & + & + & + \\
\hline & SC & + & & ++ & & & \\
\hline & SN & ++ & + & + & + & & \\
\hline & MR & ++ & ++ & + & & & \\
\hline & DR & ++ & + & ++ & + & + & \\
\hline & DpMe & + & & + & & & \\
\hline & IC & + & & + & & & \\
\hline & PPTg & + & & + & & & \\
\hline & $\mathrm{PnO}$ & ++ & + & +++ & & & \\
\hline & $\mathrm{RR}$ & + & & + & + & & \\
\hline & RtTg & + & + & ++ & & & + \\
\hline & LDTg & ++ & + & +++ & + & + & + \\
\hline & PB & ++ & ++ & ++ & & & \\
\hline & CG & ++ & + & +++ & + & + & + \\
\hline & LC & + & ++ & + & & + & \\
\hline & DMTg & & & ++ & & & \\
\hline & $\mathrm{Pn}$ & & & + & & & \\
\hline & SubB & + & & ++ & & & \\
\hline \multirow{7}{*}{ Others } & $\mathrm{VP}$ & ++ & ++ & ++ & + & + & + \\
\hline & BNST & ++ & + & ++ & + & & + \\
\hline & Septum & +++ & ++ & +++ & + & + & + \\
\hline & HT & +++ & +++ & +++ & + & & + \\
\hline & $\mathrm{NB} / \mathrm{SI}$ & + & + & + & + & + & ++ \\
\hline & $\mathrm{Hb}$ & + & & + & + & & \\
\hline & ZI & ++ & + & +++ & & & \\
\hline
\end{tabular}

Table 5. Whole-brain mapping data showing the axon-densities in different brain regions in the $m P F C_{N A C}$ and mPFC ${ }_{V T A}$ animals ( $n=3-3$ mice). AMY, amygdala; Astr, amygdalostriatal transition area; BA, basolateral amygdaloid nucleus; BNST, bed nucleus of the stria terminalis; BS, brainstem; CeA, central amygdaloid nucleus; CG, central gray; $C l$, claustrum; $C P u$, caudate putamen; CTX, cortex; DLG, dorsal lateral geniculate nucleus; DMTg, dorsomedial tegmental area; DpMe, deep mesencephalic nucleus; DR, dorsal raphe; Ect, ectorhinal cortex; Ent, entorhinal cortex; $\mathrm{Hb}$, habenula; HT, hypothalamus; I, intercalated amygdalar nuclei; IC, inferior colliculus; Ins, 
bioRxiv preprint doi: https://doi.org/10.1101/2022.02.17.480862; this version posted February 18, 2022. The copyright holder for this preprint (which was not certified by peer review) is the author/funder. All rights reserved. No reuse allowed without permission.

insular cortex; $L C$, locus coeruleus; $L D T g$, laterodorsal tegmental nucleus; $L P$, lateral posterior thalamic nucleus; MeA, medial amygdaloid nucleus; $M R$, medial raphe; NB, basal nucleus; $n R T$, reticular thalamic nucleus; PVT, paraventricular thalamic nucleus; VP, ventral pallidum; PAG, periaqueductal gray; $P B$, parabrachial nucleus; PIL, posterior intralaminar thalamic nucleus; Pir, piriform cortex; Pn, pontine nuclei; PnO, pontine reticular nucleus, oral part; PPTg, pedunculopontine tegmental nucleus; $p v$, periventricular fiber system; Re, reuniens thalamic nucleus; $R R$, retrorubral nucleus; $R S$, retrosplenial cortex; RtTg, reticulotegmental nucleus of the pons; SC, superior colliculus; SI, substantia innominata; STR, striatum; Sub, subiculum; SubB, subbrachial nucleus; TeA, termporal association cortex; TH, thalamus; Tu, olfactory tubercule; ZI, zona incerta. 


\section{References}

Adhikari A, Lerner TN, Finkelstein J, Pak S, Jennings JH, Davidson TJ, Ferenczi E, Gunaydin LA, Mirzabekov JJ, Ye L, Kim S, Lei A, Deisseroth K (2015) Basomedial amygdala mediates top-down control of anxiety and fear. Nature 527:179-185.

Akhter F, Haque T, Sato F, Kato T, Ohara H, Fujio T, Tsutsumi K, Uchino K, Sessle BJ, Yoshida A (2014) Projections from the dorsal peduncular cortex to the trigeminal subnucleus caudalis (medullary dorsal horn) and other lower brainstem areas in rats. Neuroscience 266:23-37.

Aransay A, Rodríguez-López C, García-Amado M, Clascá F, Prensa L (2015) Long-range projection neurons of the mouse ventral tegmental area: A single-cell axon tracing analysis. Front Neuroanat 9:59 Available at: /pmc/articles/PMC4436899/ [Accessed May 26, 2021].

Arlotta P, Molyneaux BJ, Chen J, Inoue J, Kominami R, MacKlis JD (2005) Neuronal subtype-specific genes that control corticospinal motor neuron development in vivo. Neuron 45:207-221.

Asher A, Lodge DJ (2012) Distinct prefrontal cortical regions negatively regulate evoked activity in nucleus accumbens subregions. Int J Neuropsychopharmacol 15:1287-1294 Available at: https://academic.oup.com/ijnp/article-lookup/doi/10.1017/S146114571100143X [Accessed April 19, 2021].

Baker A, Kalmbach B, Morishima M, Kim J, Juavinett A, Li N, Dembrow N (2018) Specialized Subpopulations of Deep-Layer Pyramidal Neurons in the Neocortex: Bridging Cellular Properties to Functional Consequences. J Neurosci 38:5441-5455 Available at: https://europepmc.org/articles/PMC6001033 [Accessed July 12, 2021].

Bakken TE et al. (2021) Comparative cellular analysis of motor cortex in human, marmoset and mouse. Nat 20215987879 598:111-119 Available at: https://www.nature.com/articles/s41586-02103465-8 [Accessed October 28, 2021].

Beier KT, Steinberg EE, DeLoach KE, Xie S, Miyamichi K, Schwarz L, Gao XJ, Kremer EJ, Malenka RC, Luo L (2015) Circuit Architecture of VTA Dopamine Neurons Revealed by Systematic Input-Output Mapping. Cell 162:622-634 Available at: https://www.sciencedirect.com/science/article/pii/S0092867415008521 [Accessed August 21, 2019].

Bossert JM, Stern AL, Theberge FRM, Marchant NJ, Wang H-L, Morales M, Shaham Y (2012) Role of Projections from Ventral Medial Prefrontal Cortex to Nucleus Accumbens Shell in Context-Induced Reinstatement of Heroin Seeking. J Neurosci 32:4982-4991 Available at: /pmc/articles/PMC3335169/ [Accessed April 19, 2021].

Britt JP, Benaliouad F, McDevitt RA, Stuber GD, Wise RA, Bonci A (2012) Synaptic and Behavioral Profile of Multiple Glutamatergic Inputs to the Nucleus Accumbens. Neuron 76:790-803 Available at: https://linkinghub.elsevier.com/retrieve/pii/S0896627312009907 [Accessed April 19, 2021].

Brog JS, Salyapongse A, Deutch AY, Zahm DS (1993) The patterns of afferent innervation of the core and shell in the ?Accumbens? part of the rat ventral striatum: Immunohistochemical detection of retrogradely transported fluoro-gold. J Comp Neurol 338:255-278 Available at: http://doi.wiley.com/10.1002/cne.903380209 [Accessed April 19, 2021].

Callaway EM et al. (2021) A multimodal cell census and atlas of the mammalian primary motor cortex. Nat 20215987879 598:86-102 Available at: https://www.nature.com/articles/s41586-021-03950- 
0 [Accessed October 28, 2021].

Carr DB, Sesack SR (2000) Projections from the Rat Prefrontal Cortex to the Ventral Tegmental Area: Target Specificity in the Synaptic Associations with Mesoaccumbens and Mesocortical Neurons. J Neurosci 20:3864-3873 Available at: http://www.ncbi.nlm.nih.gov/pubmed/10804226 [Accessed April 18, 2018].

Cassell MD, Chittick CA, Siegel MA, Wright DJ (1989) Collateralization of the amygdaloid projections of the rat prelimbic and infralimbic cortices. J Comp Neurol 279:235-248 Available at: http://doi.wiley.com/10.1002/cne.902790207 [Accessed April 19, 2021].

Christakou A, Robbins TW, Everitt BJ (2004) Prefrontal Cortical-Ventral Striatal Interactions Involved in Affective Modulation of Attentional Performance: Implications for Corticostriatal Circuit Function. J Neurosci 24:773-780 Available at: /pmc/articles/PMC6729820/ [Accessed April 19, 2021].

Cruz AM, Kim TH, Smith RJ (2021) Monosynaptic Retrograde Tracing From Prelimbic Neuron Subpopulations Projecting to Either Nucleus Accumbens Core or Rostromedial Tegmental Nucleus. Front Neural Circuits 15:639733 Available at: http://www.ncbi.nlm.nih.gov/pubmed/33732114 [Accessed February 15, 2022].

DeNardo LA, Berns DS, DeLoach K, Luo L (2015) Connectivity of mouse somatosensory and prefrontal cortex examined with trans-synaptic tracing. Nat Neurosci 18:1687-1697 Available at: http://www.nature.com/articles/nn.4131.

Domingo-Rodriguez L, Ruiz de Azua I, Dominguez E, Senabre E, Serra I, Kummer S, Navandar M, Baddenhausen S, Hofmann C, Andero R, Gerber S, Navarrete M, Dierssen M, Lutz B, Martín-García E, Maldonado R (2020) A specific prelimbic-nucleus accumbens pathway controls resilience versus vulnerability to food addiction. Nat Commun 11:1-16 Available at: https://doi.org/10.1038/s41467-020-14458-y [Accessed April 19, 2021].

Economo MN, Viswanathan S, Tasic B, Bas E, Winnubst J, Menon V, Graybuck LT, Nguyen TN, Smith KA, Yao Z, Wang L, Gerfen CR, Chandrashekar J, Zeng H, Looger LL, Svoboda K (2018) Distinct descending motor cortex pathways and their roles in movement. Nat 2018 5637729 563:79-84 Available at: https://www.nature.com/articles/s41586-018-0642-9 [Accessed September 7, 2021].

Faget L, Osakada F, Duan J, Ressler R, Johnson AB, Proudfoot JA, Yoo JH, Callaway EM, Hnasko TS (2016) Afferent Inputs to Neurotransmitter-Defined Cell Types in the Ventral Tegmental Area. Cell Rep 15:2796-2808 Available at: /pmc/articles/PMC4917450/ [Accessed April 19, 2021].

Falcy BA, Mohr MA, Micevych PE (2020) Immunohistochemical amplification of mCherry fusion protein is necessary for proper visualization. MethodsX 7:100946.

Feja M, Koch M (2015) Frontostriatal systems comprising connections between ventral medial prefrontal cortex and nucleus accumbens subregions differentially regulate motor impulse control in rats. Psychopharmacology (Berl) 232:1291-1302 Available at: https://link.springer.com/article/10.1007/s00213-014-3763-3 [Accessed April 19, 2021].

Ferino F, Thierry AM, Saffroy M, Glowinski J (1987) Interhemispheric and subcortical collaterals of medial prefrontal cortical neurons in the rat. Brain Res 417:257-266.

Ferland RJ, Cherry TJ, Preware PO, Morrisey EE, Walsh CA (2003) Characterization of Foxp2 and Foxp1 mRNA and protein in the developing and mature brain. J Comp Neurol 460:266-279 Available at: http://doi.wiley.com/10.1002/cne.10654. 
Franklin K, Paxinos G eds. (2019) The Mouse Brain in Stereotaxic Coordinates, 5th Edition, 5th ed. Academic Press. Available at: https://www.elsevier.com/books/paxinos-and-franklins-the-mousebrain-in-stereotaxic-coordinates-compact/franklin/978-0-12-816159-3 [Accessed June 23, 2021].

Gabbott PLA, Warner TA, Jays PRL, Salway P, Busby SJ (2005) Prefrontal cortex in the rat: Projections to subcortical autonomic, motor, and limbic centers. J Comp Neurol 492:145-177 Available at: http://doi.wiley.com/10.1002/cne.20738 [Accessed April 19, 2021].

Gao SH, Shen LL, Wen HZ, Zhao YD, Chen PH, Ruan HZ (2020) The projections from the anterior cingulate cortex to the nucleus accumbens and ventral tegmental area contribute to neuropathic painevoked aversion in rats. Neurobiol Dis 140:104862.

Gariano RF, Groves PM (1988) Burst firing induced in midbrain dopamine neurons by stimulation of the medial prefrontal and anterior cingulate cortices. Brain Res 462:194-198.

Geisler S, Zahm DS (2005) Afferents of the ventral tegmental area in the rat-anatomical substratum for integrative functions. J Comp Neurol 490:270-294 Available at: www.interscience.wiley.com [Accessed April 19, 2021].

Groh A, Meyer HS, Schmidt EF, Heintz N, Sakmann B, Krieger P (2010) Cell-type specific properties of pyramidal neurons in neocortex underlying a layout that is modifiable depending on the cortical area. Cereb Cortex 20:826-836 Available at: https://academic.oup.com/cercor/article/20/4/826/306157 [Accessed July 6, 2021].

Harris JA et al. (2019) Hierarchical organization of cortical and thalamic connectivity. Nature 575:195202 Available at: http://www.nature.com/articles/s41586-019-1716-z.

Harris JA, Hirokawa KE, Sorensen SA, Gu H, Mills M, Ng LL, Bohn P, Mortrud M, Ouellette B, Kidney J, Smith KA, Dang C, Sunkin S, Bernard A, Oh SW, Madisen L, Zeng H (2014) Anatomical characterization of Cre driver mice for neural circuit mapping and manipulation. Front Neural Circuits 8:76 Available at: http://www.ncbi.nlm.nih.gov/pubmed/25071457\%0Ahttp://www.pubmedcentral.nih.gov/articlere nder.fcgi?artid=PMC4091307.

Harris KD, Shepherd GMG (2015) The neocortical circuit: themes and variations. Nat Neurosci 2015182 18:170-181 Available at: https://www.nature.com/articles/nn.3917 [Accessed October 18, 2021].

Hof PR, Glezer II, Condé F, Flagg RA, Rubin MB, Nimchinsky EA, Vogt Weisenhorn DM (1999) Cellular distribution of the calcium-binding proteins parvalbumin, calbindin, and calretinin in the neocortex of mammals: phylogenetic and developmental patterns. J Chem Neuroanat 16:77-116 Available at: https://linkinghub.elsevier.com/retrieve/pii/S0891061898000659.

Hooks BM, Papale AE, Paletzki RF, Feroze MW, Eastwood BS, Couey JJ, Winnubst J, Chandrashekar J, Gerfen CR (2018) Topographic precision in sensory and motor corticostriatal projections varies across cell type and cortical area. Nat Commun 2018 91 9:1-16 Available at: https://www.nature.com/articles/s41467-018-05780-7 [Accessed December 7, 2021].

Jeong M, Kim Y, Kim J, Ferrante DD, Mitra PP, Osten P, Kim D (2016) Comparative three-dimensional connectome map of motor cortical projections in the mouse brain. Sci Rep 6:1-14 Available at: www.nature.com/scientificreports/ [Accessed July 1, 2021].

Jongen-Rêlo AL, Voorn P, Groenewegen HJ (1994) Immunohistochemical Characterization of the Shell and Core Territories of the Nucleus Accumbens in the Rat. Eur J Neurosci 6:1255-1264. 
Karreman M, Moghaddam B (1996) The prefrontal cortex regulates the basal release of dopamine in the limbic striatum: an effect mediated by ventral tegmental area. J Neurochem 66:589-598 Available at: http://doi.wiley.com/10.1046/j.1471-4159.1996.66020589.x.

Kast RJ, Lanjewar AL, Smith CD, Levitt P (2019) FOXP2 exhibits projection neuron class specific expression, but is not required for multiple aspects of cortical histogenesis. Elife 8 Available at: /pmc/articles/PMC6561705/ [Accessed July 16, 2021].

Kerstetter KA, Wunsch AM, Nakata KG, Donckels E, Neumaier JF, Ferguson SM (2016) Corticostriatal Afferents Modulate Responsiveness to Psychostimulant Drugs and Drug-Associated Stimuli. Neuropsychopharmacology 41:1128-1137 Available at: /pmc/articles/PMC4748437/ [Accessed April 20, 2021].

Kim CK, Ye L, Jennings JH, Pichamoorthy N, Tang DD, Yoo ACW, Ramakrishnan C, Deisseroth K (2017) Molecular and Circuit-Dynamical Identification of Top-Down Neural Mechanisms for Restraint of Reward Seeking. Cell 170:1013-1027.e14.

Kim EJ, Juavinett AL, Kyubwa EM, Jacobs MW, Callaway EM (2015) Three Types of Cortical Layer 5 Neurons That Differ in Brain-wide Connectivity and Function. Neuron 88:1253-1267.

Laubach M, Amarante LM, Swanson K, White SR (2018) What, if anything, is rodent prefrontal cortex? eNeuro 5:315-333 Available at: https://doi.org/10.1523/ENEURO.0315-18.2018 [Accessed June 21, 2021].

Le Merre P, Ährlund-Richter S, Carlén M (2021) The mouse prefrontal cortex: Unity in diversity. Neuron 109:1925-1944 Available at: https://doi.org/10.1016/j.neuron.2021.03.035 [Accessed June 24, 2021].

Li Z, Chen Z, Fan G, Li A, Yuan J, Xu T (2018) Cell-Type-Specific Afferent Innervation of the Nucleus Accumbens Core and Shell. Front Neuroanat 12:84 Available at: https://www.frontiersin.org/article/10.3389/fnana.2018.00084/full [Accessed July 30, 2019].

Lichtenberg NT, Sepe-Forrest L, Pennington ZT, Lamparelli AC, Greenfield VY, Wassum KM (2021) The medial orbitofrontal cortex - basolateral amygdala circuit regulates the influence of reward cues on adaptive behavior and choice. J Neurosci:JN-RM-0901-21 Available at: https://doi.org/10.1523/JNEUROSCI.0901-21.2021 [Accessed August 2, 2021].

Lodge DJ (2011) The medial prefrontal and orbitofrontal cortices differentially regulate dopamine system function. Neuropsychopharmacology 36:1227-1236 Available at: /pmc/articles/PMC3079406/ [Accessed April 19, 2021].

Mahler S V., Aston-Jones GS (2012) Fos Activation of Selective Afferents to Ventral Tegmental Area during Cue-Induced Reinstatement of Cocaine Seeking in Rats. J Neurosci 32:13309-13325 Available at: /pmc/articles/PMC3480730/ [Accessed April 19, 2021].

Matho KS et al. (2021) Genetic dissection of the glutamatergic neuron system in cerebral cortex. Nat 20215987879 598:182-187 Available at: https://www.nature.com/articles/s41586-021-03955-9 [Accessed October 18, 2021].

Mátyás F, Komlósi G, Babiczky Á, Kocsis K, Barthó P, Barsy B, Dávid C, Kanti V, Porrero C, Magyar A, Szűcs I, Clasca F, Acsády L (2018) A highly collateralized thalamic cell type with arousal-predicting activity serves as a key hub for graded state transitions in the forebrain. Nat Neurosci 21:1551-1562 Available at: http://www.nature.com/articles/s41593-018-0251-9. 
Mátyás F, Lee J, Shin HS, Acsády L (2014) The fear circuit of the mouse forebrain: Connections between the mediodorsal thalamus, frontal cortices and basolateral amygdala. Eur J Neurosci 39:1810-1823 Available at: https://onlinelibrary.wiley.com/doi/full/10.1111/ejn.12610 [Accessed June 28, 2021].

Molyneaux BJ, Arlotta P, Menezes JRL, Macklis JD (2007) Neuronal subtype specification in the cerebral cortex. Nat Rev Neurosci 8:427-437.

Morales M, Margolis EB (2017) Ventral tegmental area: Cellular heterogeneity, connectivity and behaviour. Nat Rev Neurosci 18:73-85 Available at: https://www.nature.com/articles/nrn.2016.165 [Accessed April 19, 2021].

Morishima M, Kawaguchi Y (2006) Recurrent Connection Patterns of Corticostriatal Pyramidal Cells in Frontal Cortex. J Neurosci 26:4394-4405 Available at: https://www.jneurosci.org/content/26/16/4394 [Accessed September 2, 2021].

Muñoz-Castañeda R et al. (2021) Cellular anatomy of the mouse primary motor cortex. Nat | 598:159 Available at: https://doi.org/10.1038/s41586-021-03970-w [Accessed December 2, 2021].

Oades RD, Halliday GM (1987) Ventral tegmental (A10) system: neurobiology. 1. Anatomy and connectivity. Brain Res Rev 12:117-165.

Otis JM, Namboodiri VMK, Matan AM, Voets ES, Mohorn EP, Kosyk O, McHenry JA, Robinson JE, Resendez SL, Rossi MA, Stuber GD (2017) Prefrontal cortex output circuits guide reward seeking through divergent cue encoding. Nature 543:103-107 Available at: https://www.nature.com/articles/nature21376 [Accessed April 19, 2021].

Pan WX, Coddington LT, Dudman JT (2021) Dissociable contributions of phasic dopamine activity to reward and prediction. Cell Rep 36:109684.

Paxinos G, Franklin KBJ (2001) The Mouse Brain in Stereotaxic Coordinates, 2nd Edition, 2nd ed. Academic Press. Available at: https://www.amazon.com/Mouse-Brain-Stereotaxic-CoordinatesSecond/dp/0125476361 [Accessed June 23, 2021].

Peng H et al. (2021) Morphological diversity of single neurons in molecularly defined cell types. Nat 2021 5987879 598:174-181 Available at: https://www.nature.com/articles/s41586-021-03941-1 [Accessed December 7, 2021].

Peters J, LaLumiere RT, Kalivas PW (2008) Infralimbic prefrontal cortex is responsible for inhibiting cocaine seeking in extinguished rats. J Neurosci 28:6046-6053 Available at: /pmc/articles/PMC2585361/ [Accessed April 19, 2021].

Pinto A, Sesack SR (2000) Limited collateralization of neurons in the rat prefrontal cortex that project to the nucleus accumbens. Neuroscience 97:635-642.

Riga D, Matos MR, Glas A, Smit AB, Spijker S, Van den Oever MC (2014) Optogenetic dissection of medial prefrontal cortex circuitry. Front Syst Neurosci 8:230 Available at: www.frontiersin.org [Accessed April 19, 2021].

Rojas-Piloni G, Guest JM, Egger R, Johnson AS, Sakmann B, Oberlaender M (2017) Relationships between structure, in vivo function and long-range axonal target of cortical pyramidal tract neurons. Nat Commun 2017 81 8:1-11 Available at: https://www.nature.com/articles/s41467-017-00971-0 [Accessed August 2, 2021]. 
Russo SJ, Nestler EJ (2013) The brain reward circuitry in mood disorders. Nat Rev Neurosci 14:609-625 Available at: http://www.nature.com/articles/nrn3381 [Accessed April 19, 2021].

Schmidt ED, Voorn P, Binnekade R, Schoffelmeer ANM, De Vries TJ (2005) Differential involvement of the prelimbic cortex and striatum in conditioned heroin and sucrose seeking following long-term extinction. Eur J Neurosci 22:2347-2356 Available at: http://doi.wiley.com/10.1111/j.14609568.2005.04435.x [Accessed April 19, 2021].

Seif T, Chang SJ, Simms JA, Gibb SL, Dadgar J, Chen BT, Harvey BK, Ron D, Messing RO, Bonci A, Hopf FW (2013) Cortical activation of accumbens hyperpolarization-active NMDARs mediates aversionresistant alcohol intake. Nat Neurosci 16:1094-1100 Available at: /pmc/articles/PMC3939030/ [Accessed April 19, 2021].

Shrestha P, Mousa A, Heintz N (2015) Layer 2/3 pyramidal cells in the medial prefrontal cortex moderate stress induced depressive behaviors. Elife 4.

Stuber GD, Sparta DR, Stamatakis AM, Van Leeuwen WA, Hardjoprajitno JE, Cho S, Tye KM, Kempadoo KA, Zhang F, Deisseroth K, Bonci A (2011) Excitatory transmission from the amygdala to nucleus accumbens facilitates reward seeking. Nature 475:377-382 Available at: https://www.nature.com/articles/nature10194 [Accessed April 19, 2021].

Sun X-Z, Takahashi S, Cui C, Inoue M, Fukui Y (2002) Distribution of calbindin-D28K immunoreactive neurons in rat primary motor cortex. J Med Invest 49:35-39 Available at: http://www.ncbi.nlm.nih.gov/pubmed/11901757.

Sundberg SC, Lindström SH, Sanchez GM, Granseth B (2018) Cre-expressing neurons in visual cortex of Ntsr1-Cre GN220 mice are corticothalamic and are depolarized by acetylcholine. J Comp Neurol 526:120-132 Available at: http://doi.wiley.com/10.1002/cne.24323.

Taber MT, Das S, Fibiger HC (1995) Cortical regulation of subcortical dopamine release: mediation via the ventral tegmental area. J Neurochem 65:1407-1410 Available at: http://doi.wiley.com/10.1046/j.1471-4159.1995.65031407.x.

Tasic B et al. (2016) Adult mouse cortical cell taxonomy revealed by single cell transcriptomics. Nat Neurosci 19:335-346 Available at: http://www.nature.com/articles/nn.4216.

Thierry AM, Chevalier G, Ferron A, Glowinski J (1983) Diencephalic and mesencephalic efferents of the medial prefrontal cortex in the rat: Electrophysiological evidence for the existence of branched axons. Exp Brain Res 50:275-282.

Tzschentke TM, Schmidt WJ (2000) Functional relationship among medial prefrontal cortex, nucleus accumbens, and ventral tegmental area in locomotion and reward. Crit Rev Neurobiol 14:131-142 Available at: /record/2001-18324-002 [Accessed April 19, 2021].

Ueta Y, Otsuka T, Morishima M, Ushimaru M, Kawaguchi Y (2014) Multiple Layer 5 Pyramidal Cell Subtypes Relay Cortical Feedback from Secondary to Primary Motor Areas in Rats. Cereb Cortex 24:2362-2376 Available at: https://academic.oup.com/cercor/article/24/9/2362/316533 [Accessed August 16, 2021].

van Brederode JFM, Helliesen MK, Hendrickson AE (1991) Distribution of the calcium-binding proteins parvalbumin and calbindin-D28k in the sensorimotor cortex of the rat. Neuroscience 44:157-171 Available at: https://linkinghub.elsevier.com/retrieve/pii/030645229190258P. 
Vázquez-Borsetti P, Celada P, Cortés R, Artigas F (2011) Simultaneous projections from prefrontal cortex to dopaminergic and serotonergic nuclei. Int J Neuropsychopharmacol 14:289-302 Available at: https://academic.oup.com/ijnp/article-lookup/doi/10.1017/S1461145710000349 [Accessed April $19,2021]$.

Vialou V, Bagot RC, Cahill ME, Ferguson D, Robison AJ, Dietz DM, Fallon B, Mazei-Robison M, Ku SM, Harrigan E, Winstanley CA, Joshi T, Feng J, Berton O, Nestler EJ (2014) Prefrontal cortical circuit for depression- and anxiety-related behaviors mediated by cholecystokinin: Role of $\Delta$ FosB. J Neurosci 34:3878-3887 Available at: https://www.jneurosci.org/content/34/11/3878 [Accessed April 19, 2021].

Vogt BA, Paxinos G (2014) Cytoarchitecture of mouse and rat cingulate cortex with human homologies. Brain Struct Funct 219:185-192.

Warren BL, Kane L, Venniro M, Selvam P, Richard Quintana-Feliciano X, Mendoza MP, Madangopal R, Komer L, Whitaker LR, Javier Rubio F, Bossert JM, Caprioli D, Shaham Y, Hope BT (2019) Separate vmPFC Ensembles Control Cocaine Self-Administration Versus Extinction in Rats. J Neurosci 39:7394-7407 Available at: https://doi.org/10.1523/JNEUROSCI.0918-19.2019 [Accessed April 19, 2021].

Zhang M, Eichhorn SW, Zingg B, Yao Z, Cotter K, Zeng H, Dong H, Zhuang X (2021) Spatially resolved cell atlas of the mouse primary motor cortex by MERFISH. Nat 20215987879 598:137-143 Available at: https://www.nature.com/articles/s41586-021-03705-x [Accessed December 2, 2021]. 